\title{
Exploratory Assessment of the Census of Pakistan Using Demographic Analysis
}

\author{
Asif Wazir ${ }^{1}$ and Anne Goujon ${ }^{2}$
}

\begin{abstract}
In 2017, Pakistan implemented a long-awaited population census since the last one conducted in 1998. However, several experts are contesting the validity of the census data at the sub-national level, particularly in the absence of a post-enumeration survey. We propose in this article to use demographic analysis to assess the results of the 2017 census at the sub-national level, using data from the 1998 census, from all available intercensal surveys, including three rounds of Demographic and Health Survey. Applying the cohort-component method of population projection, we subject each five first-level subnational entities to estimates regarding the level of fertility, mortality, international, and internal migration derived from the analysis of the existing data. We arrive at approximately similar results as the census at the national level: an estimated 210 million (95\% CI: 203.4-218.9) compared to 207.8 million counted (1.1\% difference). However, we found substantial sub-national variations. While there are too many uncertainties in the data used for the reconstruction to be fully confident about them, this analysis should prompt the national and the international community to ensure that a post-enumeration survey and demographic analysis are regular features of census operations of Pakistan in particular, and in developing countries with deficient data as a whole.
\end{abstract}

Key words: Census; population projections; reconstruction; Pakistan; Pakistan provinces.

\section{Introduction}

In 2017, from March to May, the Pakistan Bureau of Statistics (PBS) held the first census of Pakistan in the 21st century, 19 years after the last one, conducted in 1998. Census enumeration in Pakistan is more politically motivated than in other countries since it provides the basis for revising the political demarcations, the allocation of national and provincial assembly seats among provinces and regions, and the distribution of inter-provincial resources. Actually, perennial contentions of political parties and provincial governments have been one of the main obstacles to census taking in the country over the last few years. Despite its successful completion, the 2017 census (Pakistan Bureau of Statistics 2017) has

\footnotetext{
${ }^{1}$ United Nations Population Fund (UNFPA), Islamabad, Pakistan. Level 2, Serena Business Complex G-5/1, Islamabad, 44000, Pakistan. Email: wazir@unfpa.org

${ }^{2}$ Austrian Academy of Sciences, Vienna Institute of Demography, Vordere Zollamtsstraße 3, 1030 Vienna, Austria. Email: anne.goujon@oeaw.ac.at

Acknowledgments: This study is based on publicaly available data and was not funded. The corresponding author had full access to all data in the study and has final responsibility. We would like to thank Guy Abel, for his support in analysing the international migration pattern in Pakistan. We are grateful to members of the technical group (arranged by UNFPA) and participants in the 19th Annual Population Association of Pakistan conference for their suggestions and feedbacks. The views expressed in this article are those of the authors and do not necessarily reflect the views of the United Nations Population Fund (UNFPA). We would like to thank Associate editors and two anonymous reviewers for provided helpful comments on earlier drafts of the manuscript, which has improved the quality of the article.
} 
raised many controversies and concerns, particularly vis-à-vis the provisional results at the sub-national level, mostly for Sindh, Khyber Pakhtunkhwa (KP), and Balochistan.

These concerns are aggravated as PBS did not implement a post-enumeration survey (PES), which is an essential component to assess the potential coverage and content errors in the census enumerations. Soon after the census results were published, the majority of the political parties demanded a validation exercise that was agreed upon using five percent of the census blocks of the country but was never implemented. Performing this validation with a delay of more than two years after the census enumeration would certainly jeopardize the results for two main reasons: (1) PES and/or validation exercise should be carried out within two months after the census (United Nations 2008) because of administrative and operational issues; and (2) the demographic changes that have occurred during this period - more importantly regarding fertility and internal migration - would have influenced the total population size of the provinces.

In the absence of a PES that could either confirm or refute the results, the most sensible alternative is to reconstruct the components of population change that is, fertility, mortality, and migration (U.S. Bureau of Census 1985), using the several data sets that are available to arrive at an estimate of the Pakistani population for 2017. This reconstructed population could then be compared to the census results and checked for plausibility (Spoorenberg 2012, 2013). In the United States and in Latin American countries, demographic analysis (DA) is a standard tool to assess the census coverage at country level (Robinson 2010; Borges and Sacco 2016). Moreover, researchers recommend implementing the analysis at the sub-national level in order to account for demographic heterogeneity (KC et al. 2018). Such a reconstruction exercise was already performed for Pakistan using several data sources, for the 1998-2013 period (Wazir 2012; Sathar et al. 2014). These works also included population projections up to 2050.

A wide range of the literature has focused on the reconstruction of past population in the case of flawed or missing data. Two developments stand out: Lee's $(1974,1985)$ "inverse projections" and Wrigley and Schofield's (1981) "back projections". Inverse projections use available data on births and deaths and model them into age-specific rates that are applied to an initial population, going forward in time. Conditional on the availability of at least two unbiased estimates of population size, net migration can also be calculated (Lee 1985). Back projections are contingent on estimates at the final year and then proceed retrospectively, reconstructing population size along the way, using estimates of fertility, mortality and migration and the modelling of the open-ended age group (Lee 1985, 1993). Both inverse and back projections are deterministic and produce point estimates.

More recently, Bayesian models have been used to reconstruct past populations accounting for the dominant source of uncertainty, namely measurement error in a fully probabilistic manner (Wheldon et al. 2016, 2013). Bayesian reconstruction models both use existing data in terms of population and vital rates and expert judgement about their relative error, to derive fully probabilistic interval estimates for all vital rates. It was applied, for instance, at national level by Daponte et al. (1997) to reconstruct counterfactual estimates of the Iraqi Kurdish population between 1977 and 1990.

This article follows the methodology of DA, which resembles that of inverse projections, based on the retrospective cohort-component population projection method to estimate the population of 2017 at the time of the census, using the 1998 census data and 


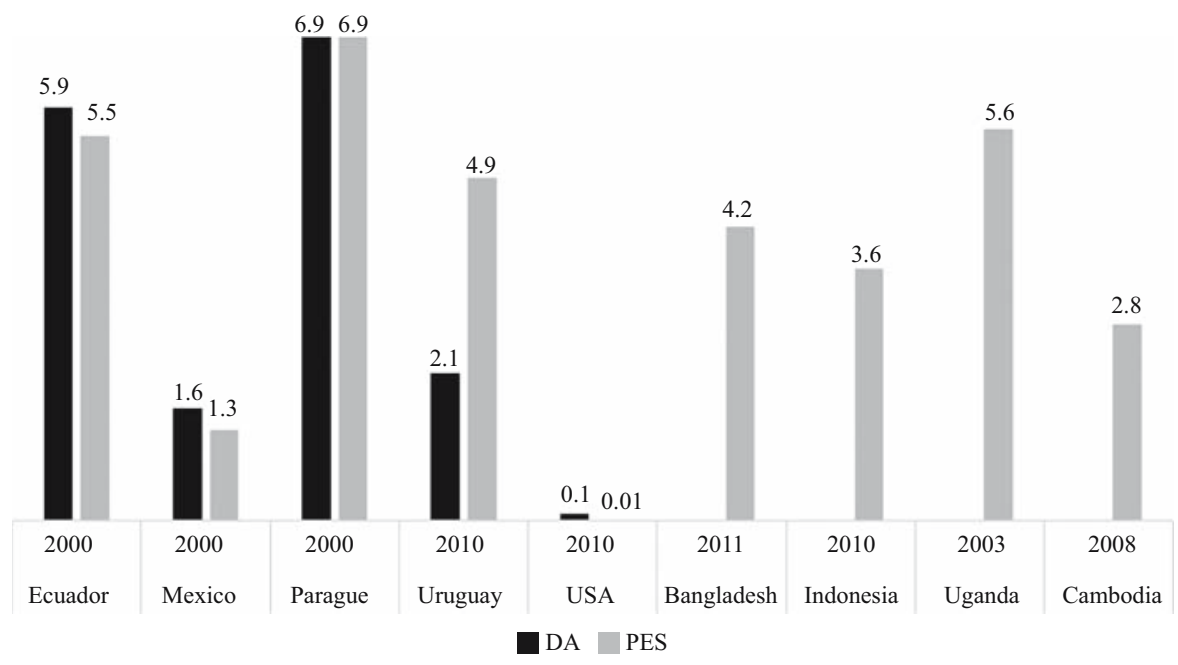

Fig. 1. Net under-count (\%) of the censuses for selected countries according to DA and PES. Source: National statistical offices of respective countries.

most available data sources about the demographic components, at the sub-national level. In addition, uncertainties surrounding vital rates are also calculated to produce point estimates as well as confidence intervals.

We built upon the analysis developed by Wazir and Goujon (2019) with the addition of several methodological advancements particularly for mortality and migration, and new data sources that have become available in the meantime. We hereby undertake a critical investigation of intercensal demographic changes in Pakistan at sub-national level. The reconstructed 2017 total population is then compared to that of the provisional census results of total population (as of March 31, 2021) for provinces and regions as to assess potential enumeration issues.

Numerous methods are available to estimate the coverage and content error of censuses. These include simple techniques of quality assurance such as internal consistency checks. Comparisons of results with other data sources including previous censuses, current household surveys and/or administrative records are also useful techniques. It is also standard practice to use DA and PES to evaluate census data, particularly in Latin American countries and the United States. If DA is implemented comprehensively, both DA and PES produce comparable results as shown in Figure 1 for Latin American countries, where except for Uruguay, the net undercount rates of census were very close according to DA and PES for example, Ecuador - $5.9 \%$ versus $5.5 \%$, and Mexico - $1.6 \%$ versus $1.3 \%$. The use of DA to assess census results and estimate net undercount rates for several sub-population (age, sex, and race) dates back to the 1940s in the United States and has been standard practice for every census ever since. Figure 1 reveals that there is a negligible difference in net under-count of the two recent US censuses according to both methods of evaluation.

\section{Why Are the Much-Awaited Census Results Contested?}

Three distinct issues could affect the quality of the census in Pakistan. First, PBS did not conduct a pilot census nor a PES, mostly because of time constraints and security issues. 
Without a validation mechanism, it is challenging to evaluate the content and coverage quality of the recent census data, and it generates doubts about the data worth.

Second, there was a confusion whether the census was conducted on either a de facto or de jure basis. While the census of Pakistan planned to use the de-jure population (recording usual residents, whether they are present at the time of the enumeration), the standard questionnaire to collect the de-jure population was not followed. The questionnaire does not allow knowing the duration of stay in the place where the person lives permanently or his/her intention to stay there for some time.

Third, the length of the enumeration period, which should be kept short in order to minimize double counting and/or omissions, which can occur due to frequent movements of the population was quite long-more than two months. This might have induced coverage and comparability issues.

\subsection{The 2017 Provisional Census Figures}

The provisional results of the 2017 census, only available for the total population, at national and sub-national level (the age-structure had not been released at the time of writing) revealed a total population of 207.8 million inhabitants in Pakistan, increasing from 132.4 million in 1998 - about a 4-million annual increase during the intercensal period (Table 1) (Pakistan Bureau of Statistics 2017).

According to the census, the total population of Punjab has increased from 73.6 million in 1998 to 110 million in 2017 (an increase of 1.9 million annually). With a $2.1 \%$ annual intercensal growth rate, the population of Punjab has the lowest growth rate among all provinces and regions. Sindh remains the second most populated province with 47.9 million inhabitants in 2017 (30.4 million in 1998) and 2.4\% intercensal annual growth rate (or 0.9 million annually). Population growth in KP was substantial: the total population grew from 17.7 million to 30.5 million with an annual growth rate of $2.9 \%$ between 1998 and 2017. Similarly, the total population of Balochistan has increased significantly from 6.6 million in 1998 to 12.3 million in 2017, with a growth rate of $3.4 \%$ - far above the national average. FATA (Federally Administered Tribal Areas) population has increased by 1.8 million from 1998 to 2017. The annual growth rate in FATA stood at $2.4 \%$ in the intercensal period (Pakistan Bureau of Statistics 2017).

Islamabad Capital Territory (ICT), the federal capital of Pakistan, has recorded the highest population growth in the country with $4.8 \%$ intercensal annual growth rate. The total population of ICT has grown sustainably from 0.8 million to 2 million from 1998 to 2017.

The census has also been implemented in Azad Jammu and Kashmir (AJK) and GilgitBaltistan (GB), self-governing territories under Pakistan control. Population growth in AJK was marginal: the population grew from three to four million with an annual intercensal growth rate of 1.6\% during 1998-2017 (Planning and Development Department, Govt. of AJ and K 2018). The population of GB was 0.9 million in 1998. However, results of the 2017 census for GB have not yet been published.

\section{Reconstruction: Data Sources and Methodology}

This study uses a wide range of sample surveys, databases and censuses conducted since the 1990s. In total, two population censuses (1998 and 2017), the United Nations World 


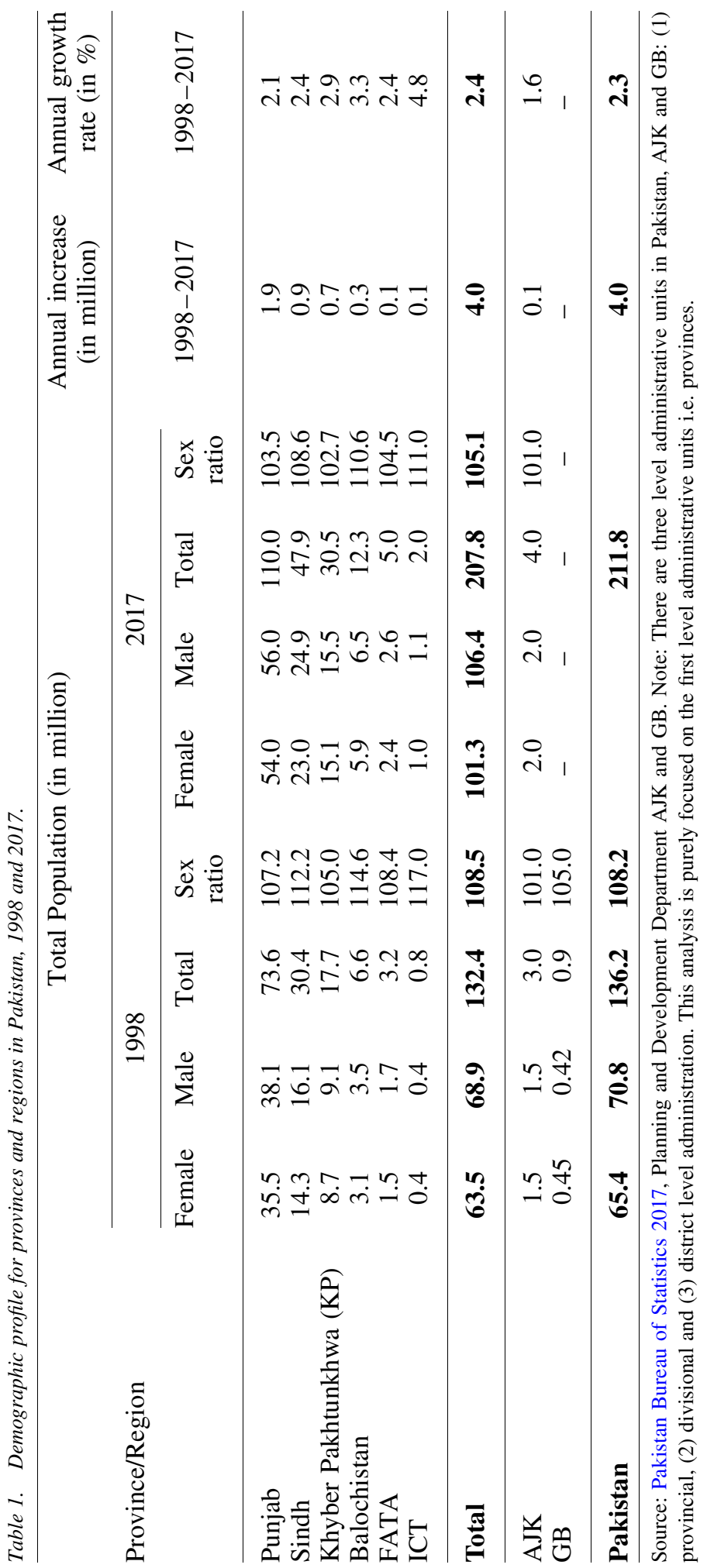


Population Prospects (United Nations 2017b), the migration flow database from Abel (2017), data sets from the Bureau of Emigration and Overseas Employment (BEOE 2019), and 28 national and provincial/regional representative sample surveys were retained for the analysis (see online supplemental data, Table 1). We covered five first-level subnational (provinces and federal) entities in our analysis (Table 1) except for AJK and GB. Our approach is bottom-up, conducting retrospective population projections for all subnational entities separately, and then aggregating them to obtain the population for the whole country. We considered that this approach would be more appropriate compared to a top-down one as it takes into consideration the dynamics of the sub-national entities to shape the national level (see also KC et al. 2018).

The retrospective projections at sub-national level follow the cohort-component method of population projection (George et al. 2004). The five-year age-sex cohorts are projected starting with $t=1998$ as the jump-off year, and are subjected to changes regarding their fertility (women), mortality, international and internal migration. The estimates for the population reconstruction are calculated in five-year periods starting from 1998-2002 to 2013-2017. The single year estimates of fertility and mortality are then converted to fiveyear averages. The contribution of international migration is negligible in overall population change during the inter-censual period of Pakistan. Still, we have integrated immigration and emigration flows in the exercise.

For internal migration, we estimated a complete origin-destination migration matrix $(8 \times 8)$ between the provinces and regions for every five-year period and used the net internal migration flows from each province. We also estimated $95 \%$ confidence intervals for all demographic components (fertility, mortality and internal migration) as explained in the relevant sections, to assess the uncertainty of the reconstructed population.

To compare the reconstructed population estimates based on the initial population at the time of the census in March 1998 with the 2017 census results, we add one step in the projections to 2018-2022 and compute the age-sex population as of 15 April 2017 using linear interpolation between the two population age distributions in 2017 and 2022. We translated the "AGEINT" spreadsheet for linear interpolation from Population Analysis System (PAS) software developed by the U.S. Census Bereau, into and $R$ code. All statistical and demographic analyses are applied in R-statistical programming language and STATA v13 (R Development Core Team 2018; StataCorp 2013).

\subsection{Smoothing Method: Loess Based Approach for the Estimation of Mortality and Fertility Indicators}

We chose the approach to fit loess regression curves to the data using a variety of smoothing parameters to vary the sensitivity to recent data trends (Murray et al. 2007). The basic loess function is:

$$
\log \left(M_{i t}\right)=\beta_{0}+\beta_{1} x_{i}+\beta_{2} z+\varepsilon
$$

where $M$ is either infant, under-five mortality or total fertility rate (respectively IMR, $\mathrm{U} 5 \mathrm{MR}, \mathrm{TFR})$, where $i \varepsilon\{$ province and region $\}$ and $t \sim$ time, $x$ is the calendar year and $z$ is an indicator variable taking value 1 if the observed values come from a direct method and value 0 otherwise, and $\varepsilon$ is an error term which is assumed to be normally distributed. $\beta_{1}$ is 
an estimate of the expected change in the given indicator for any single year, and $\beta_{2}$ is a parameter that specifies the completeness of the data for given indicators. We combine all the observations from direct and indirect sources, the loess function is fitted for each province and region separately using weighted least squares regression, with the weights corresponding to each observed values.

Let $x_{0}$ be the time point at which a fitted loess curve is required and define $\psi=\left\|x-x_{0}\right\|$ to be the separation between time points $x$ and $x_{0}$ and is the $\Phi$ maximum value for the separation. The weight function is given by:

$$
\omega=\left(1-\left(\psi /{ }_{(\Phi)}\right)^{3}\right)^{3}
$$

A weighted ordinary least-squares regression is then applied on combined data sets of given indicators (IMR, U5MR, TFR) to create a fitted value at $x_{0}$. This process is repeated for every sub-national level to generate an entire time trend.

This weighting function is tuned by a single parameter $\alpha$. This tuning takes two different forms, depending on the value of $\alpha$. When $\alpha<1$, it controls the share of the data set that is used to estimate the regression coefficient at every point in time. For example, an $\alpha$ of 0.2 means that a point is given zero weight if more than $20 \%$ of observations are closer to $x_{0}$ (i.e., with smallest values of $\omega$ ). For $\alpha \geq 1$, all data are included, and the weighting function becomes:

$$
\omega=\left(1-\left(\psi /\left(\Phi \alpha^{\frac{1}{2}}\right)\right)^{3}\right)^{3}
$$

For a minimum value of $\alpha$, we ensure that at least three data points are always included in the loess regression (as required for the estimation of the variance-covariance matrix associated with the regression coefficients) and examine the fitted loess curve corresponding to the $\alpha$ value. If the $\alpha$ value does not provide a sufficiently smooth fit to the data, then we increase $\alpha$ until a sufficiently smooth fit is achieved. The resulting $\alpha$ value is used as $\alpha_{\min }$. For the maximum value of $\alpha$, we used $\alpha_{\max }=2$.

For each value of $\alpha$ in $\left\{\alpha_{\min }, \alpha_{\min }+0.05, \alpha_{\min }+0.1, \ldots 1.0,1.1, \ldots \alpha_{\max }\right\}$, we calculate the weights for each observed indicator (IMR, U5MR and TFR) using Equation (3) and fit the loess function of Equation (1) using weighted least square regression. One thousand random draws were computed from multivariate normal distribution by the estimated regression coefficient and their variance-covariance matrix. For each of the 1,000 random draws, an estimate of the given indicators is predicted for each single year from 1980 to 2017. Finally, we pooled the estimates of the given indicators per each $\alpha$ value across the set of $\alpha$ values, a median as well as uncertainty intervals (2.5th and 97.5th centile) were computed. Further details about the loess methods can be found in Murray et al. (2007).

\subsection{Base Year Population by Age and Sex}

The quality of the base-year population data could be a major factor affecting the results of the retrospective population projections and cast a strong impact on the conclusions of study, especially since the analysis of age- and sex-specific population of the past censuses 
of Pakistan reveals no significant improvements in the accuracy of age reporting since 1972 at the national level (Ali and Sultan 2003). Thus, a thorough assessment of the 1998 population census has been conducted (as detailed in the online supplemental data). The PES of the 1998 census at sub-national level was not available, however the DA at the national level revealed that it most likely suffered from a $2 \%$ undercount (Kemal et al. 2003). Our analysis shows that the degree of accuracy in age reporting varied across regions. In particular, there was a significant under-enumeration of the $0-4$ age group in 1998, which has been documented in many settings, also in the United States (Pelletier 2020). Furthermore, we used the single-year age and sex structure of the population extracted from IPUMS (Minnesota Population Center 2017) to estimate the preference for digits of age ending with zero or five, resulting in age-heaping, which was more acute for women than for men across all provinces (see online supplemental data, Figure 3 ). The age and sex accuracy index revealed high levels of inaccuracies in the 1998 population census data at the national level, with the lowest values in Islamabad and the highest in Balochistan (online supplemental data, Table 3).

These issues point to the necessity of adjusting the reported age and sex structure of the 1998 census population before using it as a base year. We used two approaches: (1) to address the issues of age heaping and distorted sex ratio, the Arriaga's strong smoothing (Arriaga 1994) formula was applied to adjust the population by age (5-100 + years) and sex for all provinces, and Islamabad, and (2) to address the under-enumeration of the child population, we adjusted the $0-4$ age group at sub-national level using estimates of fertility and mortality in the five years preceding the 1998 census (Siegel and Swanson 2004) as explained below.

Table 2 illustrates the comparison of the 0-4 age group after adjustment with the 1998 census counts. Fertility was obtained by calculating births for each year from 1993 to 1998 based on the estimated total and age specific fertility rates (provided in Subsection 3.4) and yearly estimates of women of reproductive age (15-49 year old) (see online supplemental data, Table 4). The probabilities of survival from birth to the age at census dates were then calculated from an abridged life table of 1993-1998 (as estimated in Subsection 3.3). The estimates suggest a net undercount of $17 \%$ for boys (1.9 million) and $12 \%$ for girls (1.3 million) aged $0-4$ years old at national level, with substantial variation at sub-national level (see Table 2). The net undercount for boys aged $0-4$ years was as low as $2 \%$ in Islamabad and as high as 30\% in KP. For girls, it was lowest in Balochistan (5\%) and highest in KP (23\%).

\subsection{Estimating Mortality}

There is no comprehensive assessment of the mortality transition in Pakistan, primarily because of the lack of consistent and reliable statistics. Since independence from British colonial rule, Pakistan has conducted six population censuses: 1951, 1961, 1972, 1981, 1998, and 2017. None of them collected information on deaths that occurred within the household. Between 1960 and 1980, PBS implemented several household sample surveys and recorded the number of deaths to assess mortality levels. However, these surveys suffered from serious age-heaping and under-enumeration issues and consequently, the mortality rates were unreliable (Irfan 1986, 32). In the early 1980s, PBS started 


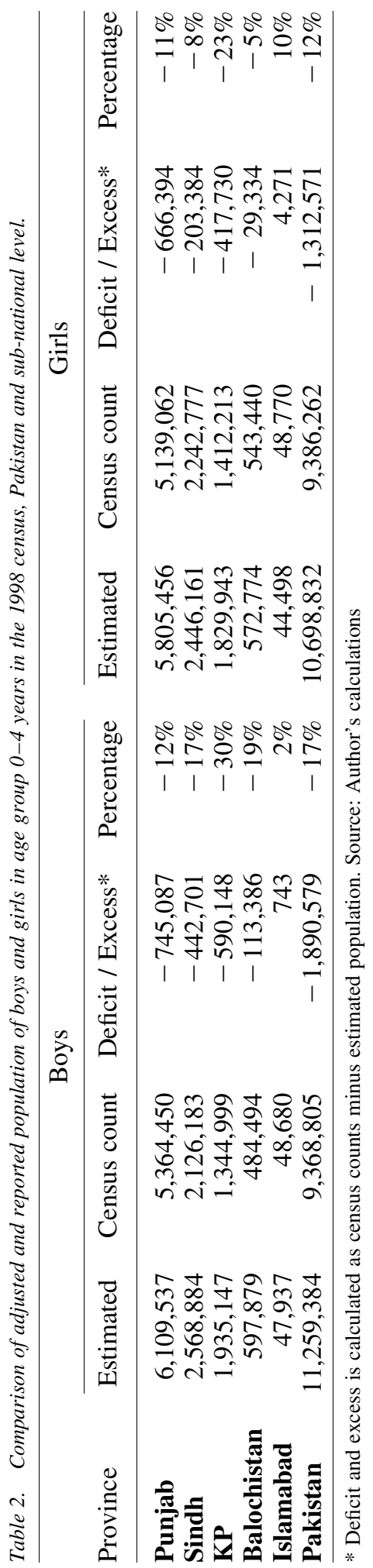


participating in the collection of vital statistics through a new type of sample surveys, that is, Pakistan Demographic and Health Surveys (PDHS). These surveys were also challenged because of coverage and reliability issues (Feeney and Alam 2003). However, they allowed the authors to estimate that the onset of the mortality transition occurred in Pakistan in the 1960s — with a substantial increase of the life expectancy from 1963 to 1973, by 6.7 years for women and 7.5 years for men (Feeney and Alam 2003).

It is uncertain when the mortality transition began in the provinces and at what stage they are currently. The data are not available to produce with a reliable estimate. For instance, in Punjab, available data seem to point to an increase in life expectancy at birth from 34.4 years to 57.5 years for women and from 32.9 years to 56.4 years for men between 1952 to 1977 (Rukanuddin and Farooqui 1987). Such an enormous increase in life expectancy within a short period (about 25 years) especially at the onset of the mortality transition - about 0.9-year increase/year for both men and women - seems unrealistic given the low socio-economic and health status of the population in this province. During the second half of twentieth century, life expectancy at birth, on average, rose by less than 0.4 years (about five months) annually in developing countries where life expectancy at birth was below 55 years (National Research Council 2000, 126).

The process of estimating life expectancies at birth for men and women for each subnational entity is implemented in three steps. First, we estimate IMR $\left({ }_{1} q_{0}\right)$ and U5MR $\left({ }_{5} q_{0}\right)$ for both sexes using robust statistical models applied to all available relevant surveys. Second, the child mortality estimates are disaggregated by sex. Finally, we combine those estimates with model life tables to estimate the life expectancy at birth and survival ratios by age. The details of each step are described sequentially below.

\subsubsection{Estimates of Infant and Child Mortality Rates}

To derive a consistent time series of IMR and U5MR, we use both full birth histories $(\mathrm{FBH})$ and summary birth histories $(\mathrm{SBH})$ data from various national and provincial representative surveys in Pakistan. Estimates of childhood mortality were computed using FBH from four rounds of PDHS (National Institute of Population Studies (NIPS) and ICF 1992, 2008, 2013, 2019) for all married women aged 15-49 years based on calendar years rather than cumulative five years preceding the survey. For regions with small sample size, we truncated the estimates based on the DHS standard methodology to calculate childhood mortality rate. Thus, in some regions the retrospective estimates are only for the three or four years preceding the survey. Use of calendar year is recommended because it brings out variation in child mortality in a clearer and more realistic manner (Pedersen and Liu 2012). In the case of FBH data, only direct estimates are included in the analysis because indirect estimates are systematically higher than direct ones (Silva 2012). Even though the Pakistan Social and Living Standard Measurement Surveys (PSLMs) provide FBH data, estimates of childhood mortality from this source were quite low (Pakistan Bureau of Statistics 2015). PSLMs may suffer from several quality issues that were not systematically assessed. Consequently, estimates from PSLMs are based on the four years preceding the survey. Indirect estimates of childhood mortality are derived from SBH (total number of children ever born and the total number of children surviving to women of reproductive age) data from Multiple Cluster Indicator Survey (MICS), 1998 Census, and other nationally representative surveys. The method used to derive indirect 
estimates from SBH (also known as the Brass method) is described in Wazir and Goujon (2019).

Following the estimation strategy of the UN Inter-agency Group for Child Mortality Estimation (UN IGME 2015), IMR and U5MR for both sexes are estimated using all nationally and provincially representative sample surveys and census since the 1990s, adjusting these data for biases if needed. We then apply loess regression to derive smoothed single-year estimates of ${ }_{1} q_{0}$ and ${ }_{5} q_{0}$ for both sexes at the level of provinces/ regions (Hill et al. 2012; Murray et al. 2007). These estimates show that the child mortality transition is underway in all sub-national entities. In 2017, the highest under-five mortality rates were found in Balochistan, followed by Punjab. In Punjab, ${ }_{5} q_{0}$ fell from a level of 112.2 deaths per thousand live births in 1998 to 87.8 in 2017, whereas it was as high as 107.3 deaths per thousand live births in Balochistan in 1998, and declined to 93.1 deaths per thousand live births in 2017. In Sindh, ${ }_{5} q_{0}$ declined from 111.5 to 88.7 deaths per thousand live births and in KP from 81.1 to 75.3 deaths per thousand live births in KP during 1998-2017 (see online supplemental data, Table 5).

IMR follow a similar pattern of decline over time in all four provinces as observed in the case of under-five mortality: ${ }_{1} q_{0}$ declined from 90.1 to 73.8 deaths per thousand live-births in Punjab and from 88.8 to 72.9 deaths per thousand live births in Sindh between 1998 and 2017. IMR in Balochistan, which was the highest among the regions of Pakistan in 2017, declined moderately during the four decades of observation, from 89.0 deaths per thousand live births in 1998 to 83.4 in 2017 . Whereas ${ }_{1} q_{0}$ in KP has declined quite substantially from 1998 to 2017 , from 97.1 to 61.7 deaths per thousand live births, considering the high levels observed in 1998 (see online supplemental data, Table 5).

\subsubsection{Life Expectancy at Birth for Men and Women}

We derive the disaggregated life expectancy at birth for men and women in two steps. First, we compute estimates of the sex ratio in ${ }_{1} q_{0}$ (SR1) and ${ }_{5} q_{0}$ (SR5) and of the sex ratio at birth (SRB) from selected sample surveys from 1998 to 2015, using the average of four years preceding the survey. Because of the two-level disaggregation (sub-national and then by sex), the sample of deaths occurring in the $0-4$ age group is too small and does not permit to produce adequate estimates of sex ratio for small provinces and regions, except for Punjab and Sindh.

In the second step, we used a robust linear regression (implemented with rlm function in R MASS package) to derive single-year estimates of sex ratios from 1998 to 2017 for Punjab, Sindh and at national level. For other provinces and regions, the average five-year rate of decline for both SR1 and SR5 at the national level is used to derive the sex ratio estimates. Predicted levels and trends of SR1, SR5, and SRB were applied to estimates of ${ }_{1} q_{0}$ and ${ }_{5} q_{0}$ for both sexes to produce time series of ${ }_{1} q_{0}$ and ${ }_{5} q_{0}$ by sex using the formulas presented in Sawyer $(2012,11)$. The details about each step are explained in Wazir and Goujon (2019).

The estimates of ${ }_{5} q_{0}$ by sex are used to derive $45 q_{15}$ for men and women separately using Coale-Demeny West model life tables. For each province and region, we computed abridged life tables by sex in the periods between 1998 and 2017 using estimates of IMR, U5MR $45 q_{15}$ as an input into the 'COMBIN' application of MORTPAK (see supplemental data, Table 6 for estimates of adult mortality). 
The last step in the estimation of $e_{0}$ by sex is to adjust the gap in life expectancy at birth between men and women (Raftery et al. 2014) using linear regression on the mortality data from the United Nations (2017b) along with provincial/regional level data of Pakistan. The gender gap is highest in ICT (2.1 more years of life expectancy for women compared to men) and lowest in both Punjab and Balochistan (1.6 years). Finally, age-sex specific survival ratios fitting the revised life expectancies at birth for male after the gender gap adjustment are estimated using the same West model life tables. The final estimates of $e_{0}$ for men and women for each province and region from 1998-2002 to 2013-2017 is presented in Figure 2. It shows the significant increase in life expectancy at birth for men and women over the last two decades, with a high level of spatial heterogeneity in Pakistan. A 95\% confidence interval is generated for male and female life expectancies at sub-national level by fitting a linear model and implemented with 'add_ci' function from "ciTools" package in R language (Haman and Avery 2014).

Men and women residing in ICT had a higher life expectancy at birth in 2013-2017 (65.7 years and 67.8 years, respectively) than those in other provinces/regions. Among other provinces, life expectancy at birth for women was lowest in Balochistan (62.3 years) and highest in KP (64.8 years) during 2013-2017. The relatively high life expectancy in KP for both men and women despite the low level of socio-economic development could be the effect of favourable environmental conditions (Mariani et al. 2009). Indeed, KP's urbanization and industrialization rates are the lowest in Pakistan, only $19 \%$ of the population lives in urban areas according to 2017 census. Detailed data on life expectancy at birth for both men and women are available in the online supplemental data, Table 10.

\subsection{Estimating Fertility}

\subsubsection{Estimating TFRs}

So far, the fertility transition in Pakistan has only been addressed at the national level (Sathar 2007), for lack of consistent and reliable data at the sub-national level. We attempt here to
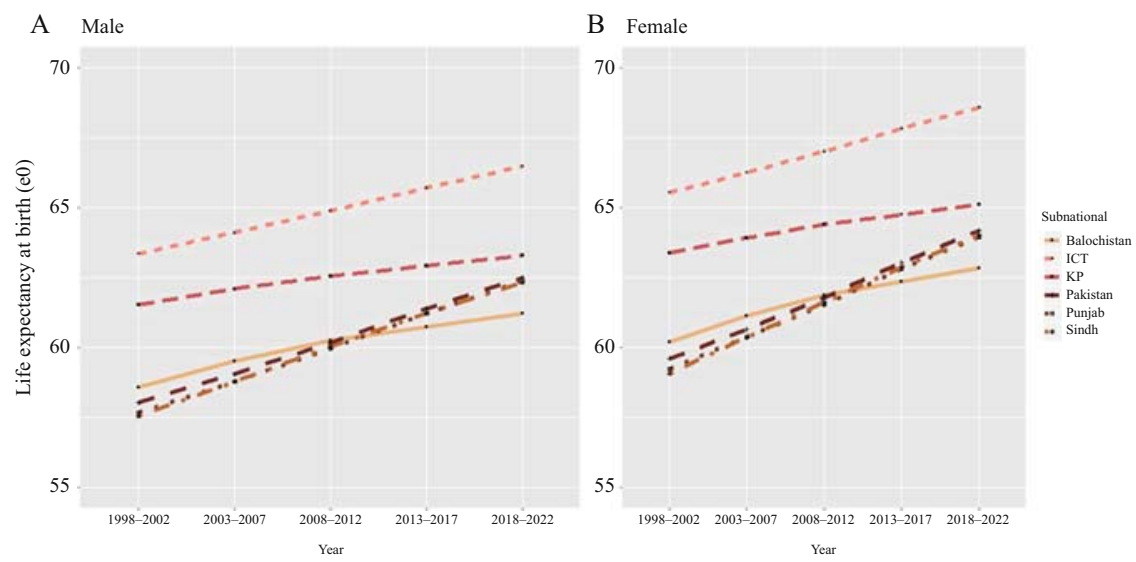

Fig. 2. Estimated life expectancy at birth of men and women in provinces and regions of Pakistan, 1998-2002 to 2013-2017.

Source: Authors' calculations. 
reconstruct sub-national fertility levels using the range of representative sample surveys and censuses since the 1990s. In the first step, adopting a similar estimation approach as for childhood mortality (see previous section), we have calculated single-year, calendar-based, retrospective TFR using the FBH data of all married women aged 15-49 years available from four rounds of PDHS for each province and region (National Institute of Population Studies (NIPS) and ICF 1992, 2008, 2013, 2019). We used tfr2, a Poisson regression-based STATA module for computing fertility rates from birth histories (Schoumaker 2013).

We also use retrospective TFRs from PSLMs, computed for three consecutive periods based on the data for the four years preceding the surveys. As well, indirect estimates of TFR are derived from SBH (total number of children ever born of women of reproductive age) data from MICS, the 1998 Census, and other nationally representative surveys, using the Arriaga method (United States, Department of Commerce, Bureau of the Census 1983).

In the second step of the estimation process, province-specific loess regressions are applied to derive time series of TFR (Figure 3). Similarly to childhood mortality, the trend line gives a consistent picture of fertility declines in the four provinces and ICT, as well as the heterogeneity at sub-national level. Loess regression also provides the $95 \%$ confidence intervals for total fertility rates that are used in the reconstruction period.

Over the last three decades, fertility in Punjab declined by 1.23 children, from 4.67 children per woman in 1998-2002 to 3.44 in 2013-2017. The TFR in Sindh stood at 5.13 children until 1998-2002, thereafter fertility continuously decreased and reached a level of 3.80 children per woman in 2013-2017. These estimates indicate that fertility in Sindh declined by 1.33 children per woman during the last three decades. Detailed data on TFR estimates are available in online supplemental data, Table 10.

The TFR in other provinces has also declined steadily, from 5.35 children in 1998-2002 to 4.00 children per women during 2013-2017 in KP. The fertility in Balochistan was at the highest level among all provinces and declined gradually during the three decades of observation, from 5.93 to 4.71 children per woman. Fertility is the lowest in 2013-2017 in ICT: 3.08 children per woman - compared with 3.55 children in 1998-2002. The loess

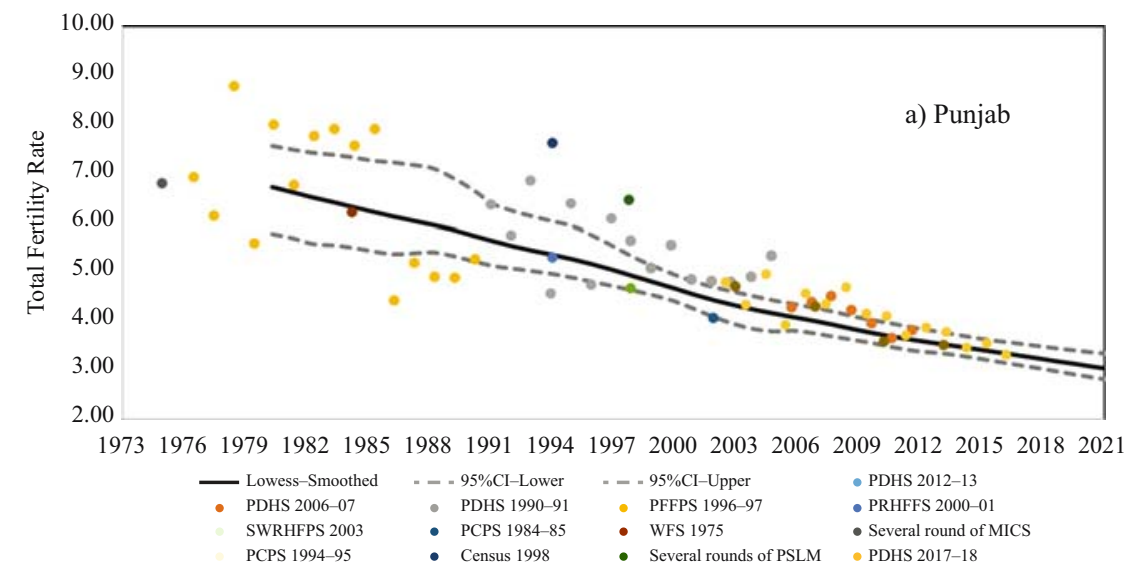

Fig. 3. Estimated Total Fertility Rate for four provinces and Islamabad and at the national level of Pakistan with $95 \%$ confidence interval, 1980-2017.

Source: Authors 'calculations. 


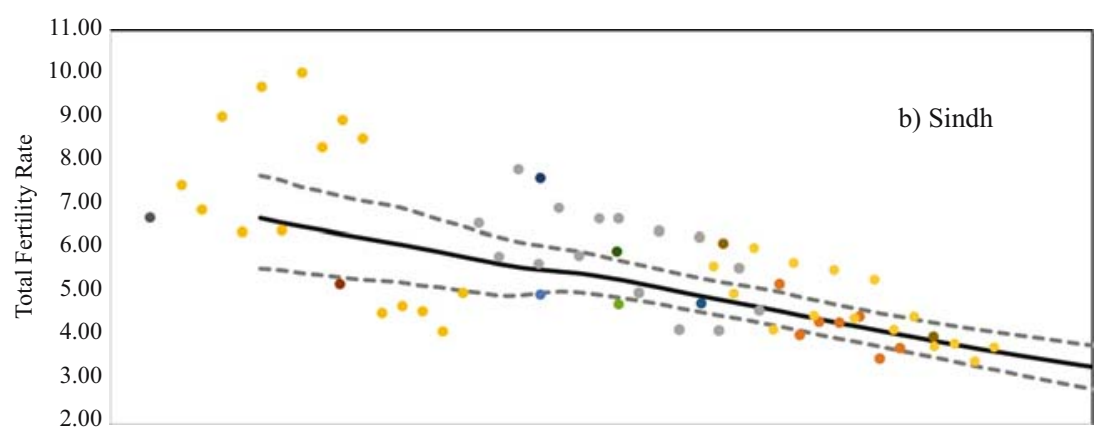

19731976197919821985198819911994199720002003200620092012201520182021
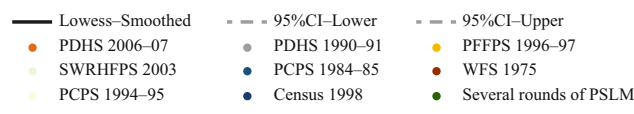

- PDHS 2012-13

- PRHFFS 2000-01

- Several round of MICS

- Several rounds of PSLM

- PDHS 2017-18

Fig. 3. Continued.

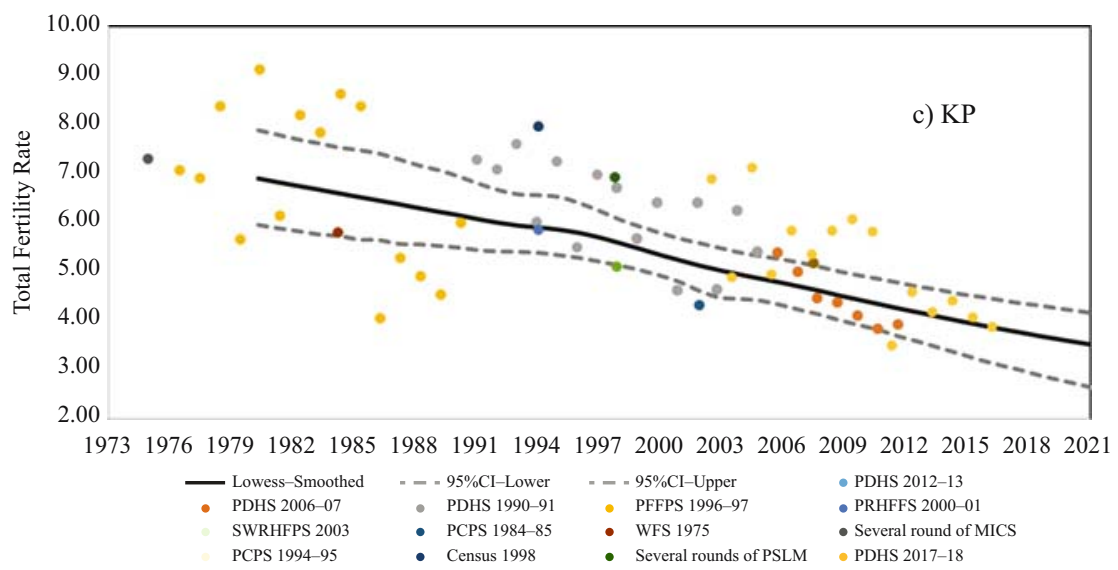

Fig. 3. Continued.

regression predicts a rapid pace of fertility decline during the coming period of 2018 to 2022, which is unlikely considering the marginal decline over the 2006-2017 period - 0.5 children. Therefore, we used Autoregressive Integrated Moving Average (ARIMA) model of order $(1,1,0)$ with drift term to forecast the fertility rate for 2018-2022 (see online supplemental data, Table 8).

\subsubsection{Age-Specific Fertility Rates}

It is important to note that birth histories are increasingly truncated at older ages the further we move back in time from the survey date. Hence, there is a need to adjust the fertility outcome of the older women of reproductive age. The procedure developed (Schoumaker 2013) holds constant the age-specific distributions of fertility estimated around the time of the survey for the entire 15-year period preceding the survey, possibly overestimating fertility. Age-specific fertility rates have been estimated separately as explained below.

Estimating age-specific fertility rates (ASFR) in Pakistan at the sub-national level is complicated by the lack of reliable and time-consistent rates. Furthermore, due to random 


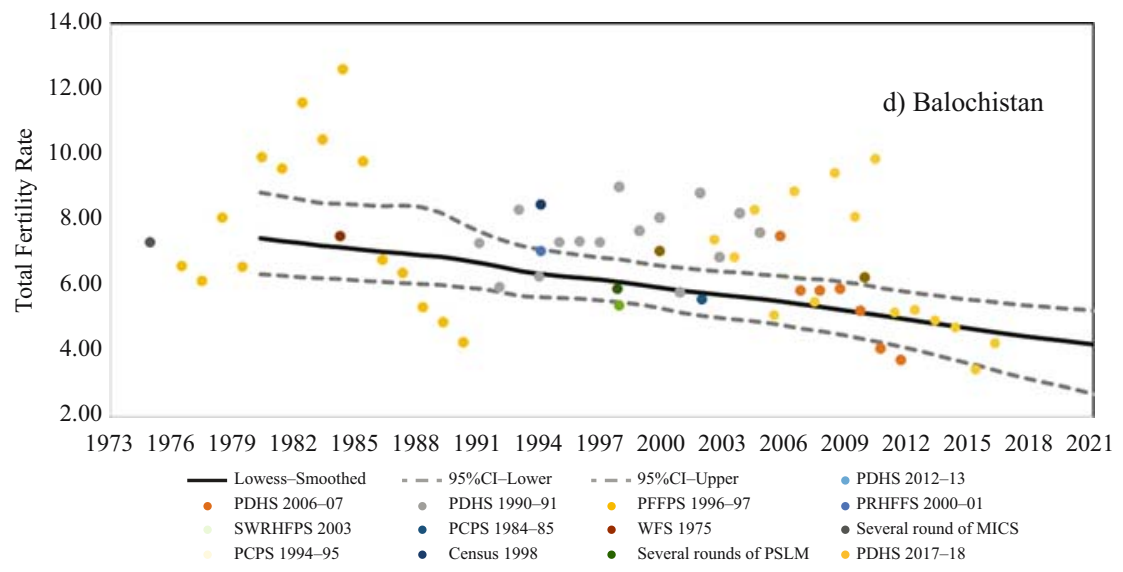

Fig. 3. Continued.

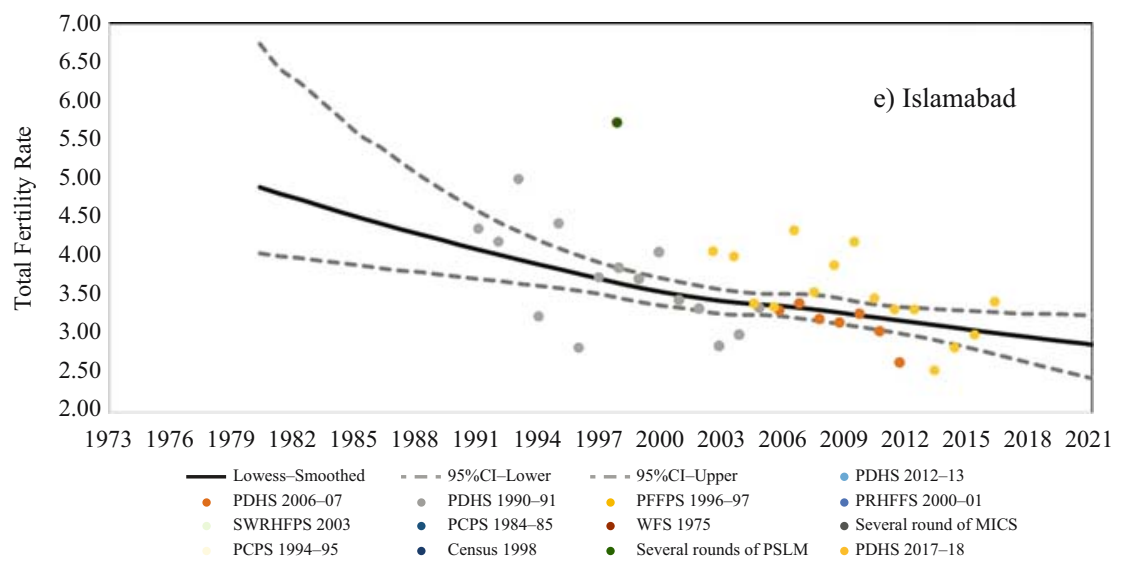

Fig. 3. Continued.

fluctuations in fertility rates over time, estimates based on interpolation between surveys tend to result in irregular age patterns, particularly for the smaller sub-national entities.

We applied a relational model, which relates the age profiles to be fitted or projected to a standard age schedule (Booth 1984), the Gompit regression model. It is defined as:

$$
Y(x)=-\log \{-\log (F(x))\}
$$

where $F(x)$ is the cumulative relative ASFR at age x. Let $Y_{s}(x)$ equals Gompit $\left(F_{s}(x)\right)$ of the standard fertility schedule. Then a new ASFR schedule $Y(x)$ can be defined in terms of $Y_{s}(x)$ as:

$$
Y(x)=\alpha_{0}+\beta_{0} Y_{s}(x)
$$

Using the age-specific fertility patterns of each national and sub-national level from all surveys from 1990 to 2012 (eight surveys where ASFR were available), we empirically estimate $\alpha_{0 i}$ and $\beta_{0 i}$-where $i$ refers to the year of survey - in Equation(5) using standard age schedule of fertility adopted from Booth (1984). A cumulative ASFR schedule may be recovered from $Y(x)$ by reversing the above transformations. 


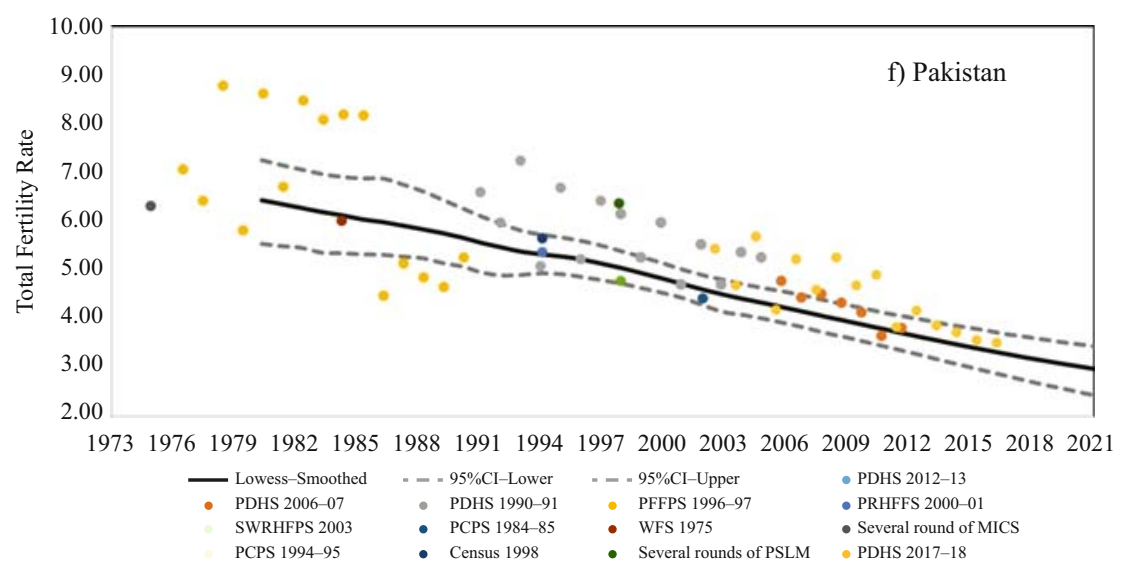

Fig. 3. Continued.

The next task is to estimate the unique value of $\alpha$ and $\beta$ by controlling time variation. We aim to relate both parameters to the TFR. Based on maximum R-square, we find power fit to be best for $\beta$ and logarithmic fit for $\alpha$.

$$
\begin{array}{r}
\beta=1.8351(\text { TFR })^{-0.526} \\
R^{2}=0.2513
\end{array}
$$

And

$$
\begin{array}{r}
\alpha=-0.111 \log (\text { TFR })+0.0382 \\
R^{2}=0.0416
\end{array}
$$

Using these relationships, the sub-national specific ASFRs can be derived for the given TFRs in each period.

The age pattern of fertility in Pakistan shows the typical pattern of a country in the middle stage of the demographic transition, with childbearing peaking in the age group 25-29 years and declining afterward (Wazir 2012,38), and still substantial early childbearing in the age group 15-19 years (see Figure 4 ). This pattern contributes to high fertility, as it does in many high fertility countries (United Nations 2013), with women spending many years in the reproductive span, with increased health risks for both mothers and children, and reduced education and employment opportunities. The unchanged age pattern over the years also reflects the sustained preference of Pakistani for a large family size (Wazir 2018).

\subsection{Estimating International Migration}

In-depth analysis of international migration is difficult in Pakistan because existing data are incomplete and do not effectively capture contemporary intensities and patterns.

According to estimates by the United Nations, there were 5.9 million Pakistani residing in another country in 2015 (about 2.7 million Pakistani in Gulf countries). This figure was 3.4 million in 2000 (United Nations 2017a). The United Nations Refugee Agency 

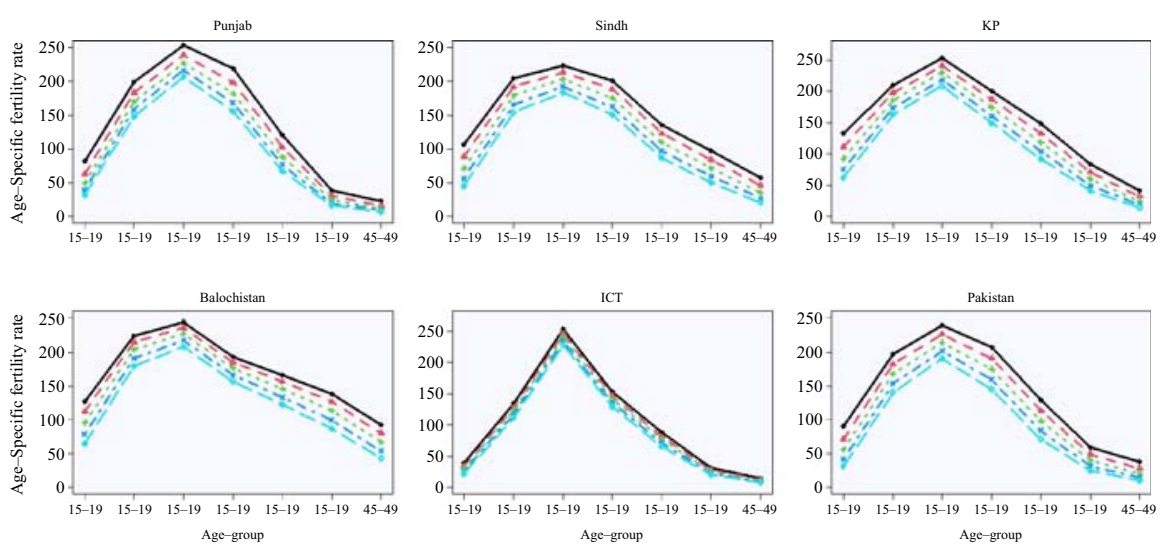

$-1996-2002--2003-2007 \cdots 2008-2012 \cdots 2013-2017 \rightarrow 2018-2022$

Fig. 4. Estimated Age Specific Fertility Rate Rate for four provinces and Islamabad and at the national level of Pakistan, from 1998-2018.

Source: Authors' calculations.

estimates that in 2018, there were about 390,000 refugees and asylum seekers originating from Pakistan, including 180,000 people who were returned refugees or internally displaced in Pakistan. However, there is no comprehensive estimate about irregular migrants from Pakistan. Cibea et al. (2013) pointed at approximately 300,000 people migrating from Pakistan each year using irregular channels.

The BEOE of Pakistan reports that about 5.8 million Pakistanis migrated legally for overseas employment in the Gulf countries during 2005-2015. Large-scale labour migration of Pakistanis to the Gulf region started with the oil boom in the late 1970s and continued in the context of the volatile political situation in Pakistan combined with issues related to poverty and unemployment. The Gulf countries also have the advantage of geographical and religious proximity. However, official data do not fully capture the total overseas migration because highly skilled Pakistanis, who migrate especially to non-GCC countries, usually do not register with government agencies. It was estimated that only $2 \%$ of Pakistani workers going abroad for employment formally went through the registration procedure with the overseas employment corporation (Ministry of Overseas Pakistanis and Human Resource Development 2016). Since the early 1990s, there has been a growing trend among well-off families to send their male children abroad for educational purposes, most commonly to the United States, United Kingdom, and other European countries. These men often establish themselves overseas and are later joined by their dependents (Gazdar 2003).

While there is a lack of official data, the number of immigrants to Pakistan is estimated to be very low, except for the continuous influx of refugees from Afghanistan, since the early 1980s (following the Soviet invasion). The 2005 Afghan population census estimated that Pakistan hosted some three million Afghans, the largest Afghan diaspora in the world, and the majority of this Afghan population (about 88\%) were residing in KP and Balochistan (Ministry of States and Frontier Regions et al. 2005). The 2005 census also showed that about $89 \%$ of the Afghans who settled in camps and $78 \%$ who settled in non-camps areas were not willing to return to Afghanistan, in tandem with the deterioration of living conditions in their country. Because of the language and cultural similarities, many Afghan refugees have become 
permanent resident in Pakistan. According to UN estimates, in 2012, about 2.3 million Afghanis had settled permanently in Pakistan, and 1.6 million still had refugee status.

Other immigrant groups in Pakistan - though smaller in number - originate from India, Bangladesh, Myanmar, China, Middle Eastern and Central Asian states. Most immigrants register as foreign workers or skilled technical experts under bilateral agreements. Recently, with increasing investment under the China-Pakistan Economic Corridor, labour force migration from China has increased, mainly to GB, Punjab, and Balochistan. The number of Chinese engineers working in Pakistan increased from 3,000 in 2008 to 13,000 in 2011 (Cibea et al. 2013).

However, migrant stock data do not capture migration flows and particularly the timing and duration of migration movements. For our purpose, we would require consistent international migration flows (both in-and-out) over five-year periods from 1998 to 2017. In a series of pivotal studies, Abel developed a methodology to derive global estimates of origin-destination migration flows by using stock data (Abel 2013, 2017; Abel and Sander 2014). We used Abel's five-year estimates of total emigration and immigration flows from 1990 to 2010 for Pakistan (Abel 2017), adjusting it with the yearly registered emigrants from BEOE official data from 1990 to 2016. A smooth spline is applied to reconstruct the annual total emigration and immigration flows during the period of interest. Next, estimated annual migration flows are distributed among the provinces and regions using the five-year average proportional share calculated from BEOE data. For gender division of migration, we used the average of South-Asian migrant flows by gender (i.e., $60 \%$ men and $40 \%$ women) in all provinces and regions (Abel 2017), which we assumed to be constant through the reconstruction period. As the absolute number of international migrants is small compared to the total population of Pakistan, the uncertainty range is not calculated. The estimated migration flows were used in both lower and upper confidence intervals. Data on international migration flows are available in the online supplemental data, Table 10. The age pattern of international migration is obtained using the sevenparameter model of migration (Rogers and Castro 1981), adopting the parameter estimates of young standard age-profiles developed by Raymer and Rogers (2006).

\subsection{Internal Migration}

For the sub-national DA, internal migration plays an important role in shaping the demographic landscape. However, little progress has been made to quantify the spatiotemporal dynamics of internal migration and its impact on population growth in the Pakistani context. According to stock data from the 1998 census, about four million people had internally migrated within and between the provinces and ICT during the ten years preceding the census. Out of these four million, approximately $53 \%$ had migrated between the four provinces and ICT (Karim and Nasar 2003), about 24\% to Punjab and $19 \%$ to Sindh. Unfortunately, the 2017 census did not capture any information on internal migration. Thus, it needs to be reconstructed using other indirect methods.

\subsubsection{Finding Migrants in the Labour Force Surveys}

Recently, labour force surveys (LFS) and other household surveys have been frequently used to estimate internal migration flows in the absence of direct data in different settings 
(Willekens et al. 2017; Marti and Rodenas 2007; Wisniowski 2017). LFS that have been conducted yearly since 1963 by PBS include questions about the place of birth, previous place of residence and duration of stay in the current place. While these data have not yet been used to quantify internal migration flows in Pakistan, we hereby assume that they are a suitable source with large samples and long-time series.

In this section, we present the method for estimating bilateral migration flows from survey data. We used data from five rounds of the LFS conducted from 1999 to 2015, which were using a multistage, stratified sampling design to collect data on the sociodemographic characteristics of the population including internal migration. These five data sets are nationally representative and were chosen to reflect the trend over the 15-year period. LFS measures migration using the transition conceptual framework, that is, comparison of people's location at one point in time with that at another point (Rees et al. 2000). Although LFS surveys include all sub-national entities, we only include estimates for four provinces and ICT in the model.

The United Nations introduced the threshold to distinguish long-term migration (intention to stay for at least one year) to short-term migration (visiting for less than one year). In order to increase the sample size, in the case of Pakistan, we considered shortterm migration to refer to people who had been residing in a place during the last four years or less coming from another place. A limitation is of course that multiple transitions cannot be identified during the observation period because this information is not recorded. Bilateral migration flows between the provinces and regions for the population of ten years of age and over - that is, 8x8 origin-destination migration matrix - are computed by applying sample weights from each LFS round using STATA v13 (StataCorp 2013). Because LFS are not implemented in FATA, missing values have been generated predominantly for the destination of migrants to this region. Even though FATA is mostly a region of origin of internal migrants (either in the form of labour migration to more developed provinces or internally displaced persons due to unrest), some skilled labour immigration to this region has also been observed. To overcome the lack of data, we assigned, conservatively, about one percent of the total sample of migrants to FATA.

Other limitations may have to do with the low coverage of internal migrants in the LFS due to non-response, imperfect coverage of the migrant population in the sampling frame, undercount due to the emigration of entire households, and non-sampling variability (Wisniowski 2017). Moreover, KP and FATA have hosted a significant number of refugees and internally displaced persons that might not be counted in the LFS (UN Office for the Coordination of Humanitarian Affairs (OCHA) 2017). Computing origindestination migration rates from LFS would be problematic because migration rates are considered as occurrence-exposure rates that are obtained dividing the total number of migrants by the population at risk, weighted by the duration of exposure (Willekens et al. 2017), which we do not have. Instead of using migration rates, we adopted the following approach to compute migration flows. The share of migrants to the total sample size is computed as $p_{m}=n_{m} / n$, where $m$ denotes the migrant sample size and $n$ is the total sample size. Using the inter-census population growth rate of 1998-2017, the total population of each province and region $\left(P_{i t-1}\right)$ is exponentially interpolated for the year $t-1$, where $t$ is the year of each LFS. Next, the total number of migrants is computed as $\mathrm{T}_{t}=p_{m} \times P_{i t-1}$. 
Next, using the origin-destination matrix above mentioned, the ratio of migrant count $\mu_{i k}=n_{i k} / n_{m}$ is computed, where $n_{i k}$ indicates the marginal sum of the matrix, $k \varepsilon\{$ Origin, Destination $\}$ and $i \varepsilon\{$ province and region $\}$. Finally, internal migration flows are obtained by multiplying the total population of the appropriate year as $y_{i k t}=\mu_{i k} \times \mathrm{T}_{t}$. With known margins $y_{i k t}$ the origin-destination migration matrix is further filled proportionally.

\subsubsection{A Statistical Model of Migration Flows}

Migrants usually constitute a tiny fraction of the total sample size of LFS: less than $1 \%$ from 1998 to 2014, except in 2014-2015 round, in which the sample was 3.6\%. To surmount this shortcoming, we build a model to adjust for statistical bias, and derive data for years without LFS, using indirect variables in a Poisson regression model. To assess whether the volume of migration flows among origin and destination regions differ, we introduced several explanatory variables in the model including the population size, the area of origin and destination, along with the distance between the capital cities of provinces and regions. To capture the change in migration flows over time, we also introduced the year as an independent variable.

To summarize, $y_{i j t}$ is the expected migration flow from origin $i$ to destination $j, P_{i}$ is the population in the region of origin $i$ and $P_{j}$ is the population in the region of destination $j, d$ is the distance between the capital city in origin $i$ and destination $j, t$ is the year and $Z$ the dummy variable for $i, j=1,2,3 \ldots, 8 . \varepsilon_{i j}$ is the random residual. In a first step, we included in the model the surface area (in $\mathrm{km}^{2}$ ) of the origin and destination regions to estimate the coefficients using a generalized linear model (GLM). Then a stepwise regression algorithm (stepAIC of R MASS package) was applied to the starting model, in which we eliminated surface areas of both origin and destination and retained all other explanatory variables. The final model is presented in Equation 8. All variables in the model are highly significant and pseudo- $R^{2}$ for the final model was 0.809 .

$$
y_{i j t}=\exp \left(\text { Intercept }+\alpha_{1} P_{i}+\alpha_{2} P_{j}+\varphi d_{i j}+b_{1} z_{i}+b_{2} z_{j}+\delta t+\varepsilon_{i j}\right)
$$

We also perform an over-dispersion test of the model in Equation 8 using dispersiontest from "AER" package (Kleiber and Zeileis 2008). There is clearly evidence of overdispersion in the model. While the obvious solution would be to use quasi-Poisson or negative-binomial distribution, it results in similar fitted values as the Poisson regression model and the distance variable becomes insignificant. Therefore, we prefer to use the original Poisson model. A 95\% confidence interval is generated for both in and out internal migration separately using the above model and implemented with 'add_ci' function from "ciTools" package in R language (Haman and Avery 2020). We have applied the Rogers and Castro (1981) model to derive the age pattern of in- and out-flows of internal migration. However, due to the small size of the flows in some provinces / regions, the model does not perform well, and hence we had to resort to net internal migration for the reconstruction model (see online supplemental data, Table 10). Net internal migration is proportionally adjusted using respective age distribution of the provinces and Islamabad for a given time period. 


\subsubsection{Bilateral Patterns}

To depict the pattern of estimated bilateral migration flows over time, two circular migration plots are shown in Figure 5 for 1993-1997 and 2013-2017. Plots were created in R using "migest" package (Abel 2018). The direction of the flow is indicated by the arrowhead. The number on the outer section axis indicates the size of migration flows (in thousands).

In 1993-1997, Punjab was the destination of most migrants from other parts of the country, with a net gain of about 0.19 million migrants. The net gain has increased significantly during the intercensal period and reached 0.42 million in 2013-2017. Most migrants to Punjab were coming from Sindh, KP, and FATA in both periods. In 2013-2017, Balochistan has also become a major sending province to Punjab. The largest out-migration flows from Punjab were to Sindh, KP, and ICT.

Changes in the size of migration flows in Sindh revealed an interesting pattern. The net gain of internal migration reversed during the intercensal period, from a tiny negative number (about -3,000) in 1993-1997 to 0.34 million in 2013-2017. The most visible pattern is that net gains in Sindh have surpassed that of Punjab most likely due to the improved security and economic situation in Sindh. In the last two decades, significant flows of immigration to Sindh were originating from Punjab, KP, and FATA, whereas, the destination of the Sindhi migrating population was mostly to Punjab, KP, and ICT (see Figure 5).

$\mathrm{KP}$ and FATA have experienced significant out-migration flows because of the undergoing armed conflict during the period: In KP, we estimate a net loss of $-40,000$ in $1993-1997$ to a gain of 0.2 million in 2013-2017. The large influx of migrants to KP in the last period is primarily due to armed conflicts in FATA and other northern areas of the country. During the last two decades, most inflows to KP came from Punjab, Sindh, and FATA, whereas the destination of KP migrant population was mostly to Punjab, Sindh, and ICT. It is important to note that this migration in KP and FATA do not fully capture the flow of refugees from Afghanistan.
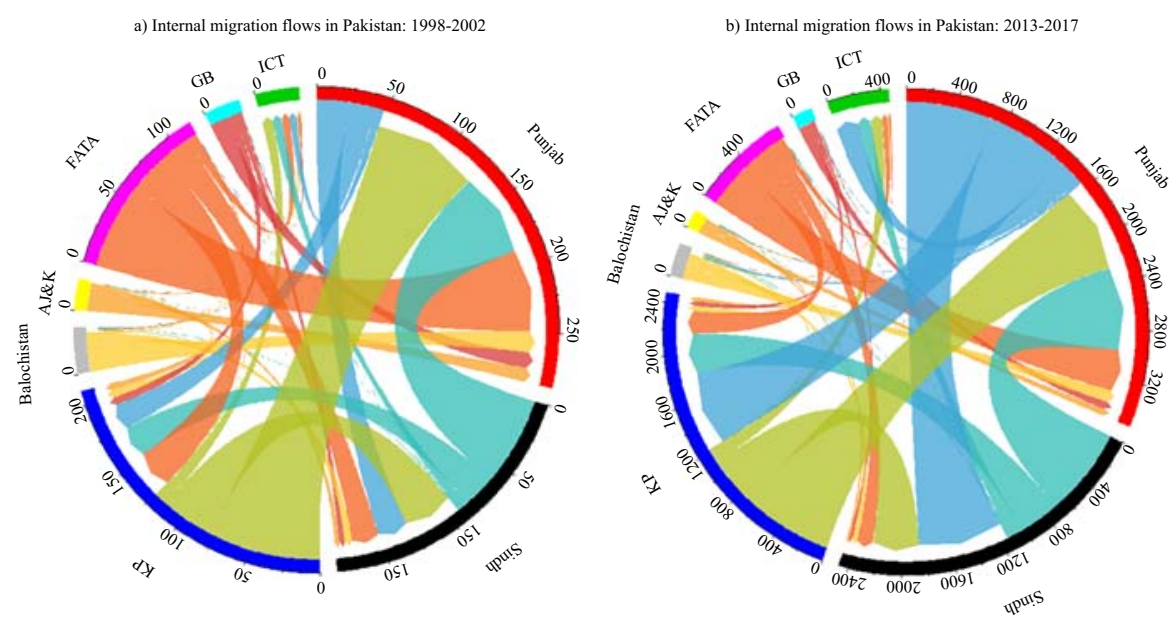

Fig. 5. Estimated bilateral internal migration flows in Pakistan, 1998-2002 and 2013-2017 (flows in000s). Source: Authors' calculations. 
Large flows, mostly labour migrants, from other provinces to ICT are also estimated, to reach 0.7 million in 2013-17. While the flows for Balochistan and other regions are contributing a tiny proportion to the total number of internal migrants.

\section{Results of Retrospective Population Projections}

We used the above-mentioned estimates of fertility, mortality, and migration (both international and internal) to project forward population by age and sex at sub-national level using the 1998 census as the base year. By comparing the reconstructed 2017 population with the official results of the 2017 census population using a goodness-of-fitstatistic computed as the average absolute deviation (AAD), it emerges that the reconstructed total population of each province and region significantly differs compared to the official figure.

\subsection{Total Population}

Figure 6 illustrates the difference in population between the reconstructed 2017 population and the enumerated population by the census (A) and the AAD (B). The two exercises lead to similar results at the national level. The reconstructed population (excluding AJK and GB) is 210 million (95\% CI: 203.4-218.9) in 2017, a difference of 2.3 million compared with the reported census population size (210.0 compared to 207.8 million), hence a marginal difference of $1.1 \%$ (see Figure 6).

However, we find more considerable variations at the sub-national level. For the two largest provinces - Punjab and Sindh - the reconstructed population is much larger than

A

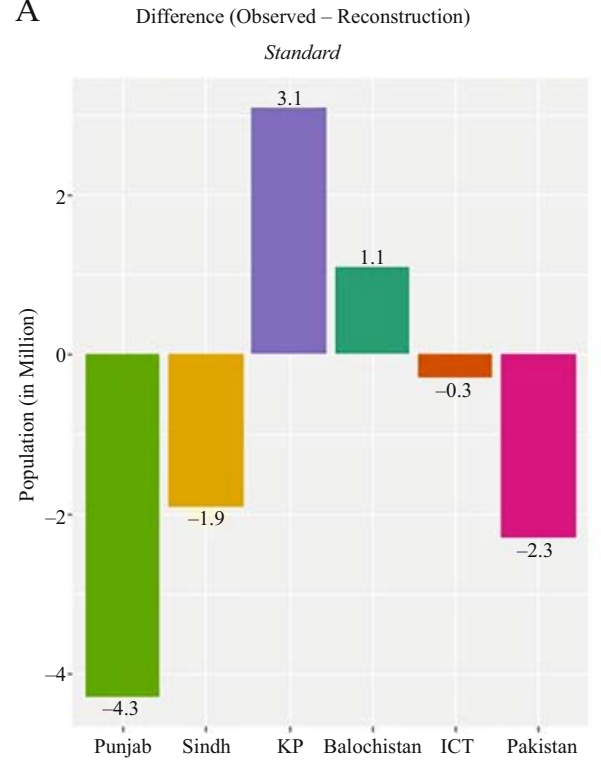

$\mathrm{B}$
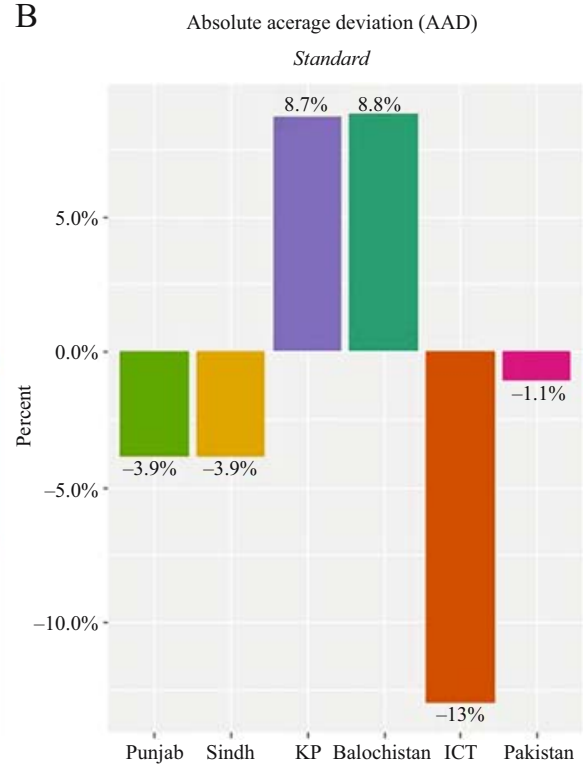

Fig. 6. Difference of the 2017 census results to the retrospective population projections (A) and $A A D(B)$ for Pakistan, by provinces and regions.

Source: Authors' calculations. Note: Total difference for Pakistan excluded the AJK and GB. 
the census population. The difference between census estimates and the reconstruction in the capital city for which coverage should be logically better could be due to flawed migration estimates. Another explanation could be that people want to be counted at their region of origin for several reasons, for example, identity, political, social, and others. The reverse is shown for KP and Balochistan, which have a lower population in the reconstruction compared to the census. The retrospective population projections indicate that the total population of Punjab and Sindh would be 114.3 million (95\% CI: 112.3 117.8 ) and 49.8 million (95\% CI: 48.0 - 52.1) in 2017, a difference of 4.3 (AAD: $3.9 \%$ ) and 1.9 million (AAD: 3.9\%) with the official census estimates, respectively. For ICT, though the difference is trivial in absolute number (0.3 million), AADs are significantly higher, compared to Punjab and Sindh.

As mentioned, the retrospective population projections point at the possibility of overenumeration of the population for KP and Balochistan. The reconstructed total populations for KP (including FATA) and Balochistan are 32.4 million (95\% CI: 30.6 - 34.4) and 11.3 million (95\% CI: 10.4 - 12.2) in 2017, a difference of about 3.1 and 1.1 million, respectively. The AAD values for $\mathrm{KP}$ and Balochistan stood at $8.7 \%$ and $8.8 \%$, indicating a significant difference from the census figures.

To assess the sensitivity of the reconstruction to the demographic components of population growth during the intercensal period, in addition to the standard variant (that refers to the retrospective population projections above mentioned) we also ran two additional population reconstruction scenarios: (1) without internal migration, and (2) without internal and international migration - just considering natural increase. Without internal migration, the population of Punjab and Sindh would have reached 112.3 and 49.4 million in 2017, a difference of 2.0 million in Punjab and 0.4 million in Sindh from the standard variant (Table 3 ). The decrease in population due to internal migration in KP and Balochistan in 2017 is 2.3 and 0.4 million. Thus, the reconstruction is very sensitive to estimates of internal migration in some provinces/regions, that is, Punjab, and KP.

The impact of international migration is shown in the difference between the natural increase variant and the without-internal migration variant. A significant number of people

Table 3. Total population of Pakistan at the sub-national level in 2017 according to the census and to three population projection scenarios (in millions). $95 \%$ confidence interval in the parenthesis.

\begin{tabular}{lrrrr}
\hline Provinces/Regions & \multicolumn{2}{l}{ Total Population in 2017} & \\
\cline { 2 - 5 } & $\begin{array}{c}\text { Census } \\
\text { population } \\
\text { (official) }\end{array}$ & $\begin{array}{c}\text { Population } \\
\text { reconstruction } \\
\text { (standard variant) }\end{array}$ & $\begin{array}{c}\text { Without } \\
\text { internal } \\
\text { migration }\end{array}$ & $\begin{array}{r}\text { Natural } \\
\text { increase }\end{array}$ \\
\hline Punjab & 110.0 & $114.3(112.3-117.8)$ & 112.3 & 116 \\
Sindh & 47.9 & $49.8(48-52.1)$ & 49.4 & 50.1 \\
KP & 35.4 & $32.4(30.6-34.4)$ & 34.7 & 37.2 \\
Balochistan & 12.3 & $11.3(10.4-12.2)$ & 11.7 & 11.9 \\
ICT & 2.01 & $2.27(2.24-2.31)$ & 1.1 & 1.2 \\
Pakistan & $\mathbf{2 0 7 . 7}$ & $\mathbf{2 1 0 . 0}(\mathbf{2 0 3 . 4 - 2 1 8 . 9}$ & $\mathbf{2 0 9 . 2}$ & $\mathbf{2 1 6 . 3}$ \\
\hline
\end{tabular}

Note: Population reconstruction refers to the retrospective population projections of 2017 and serves as the reference to assess the demographic effect of other population scenarios. Source: Authors' calculations. 


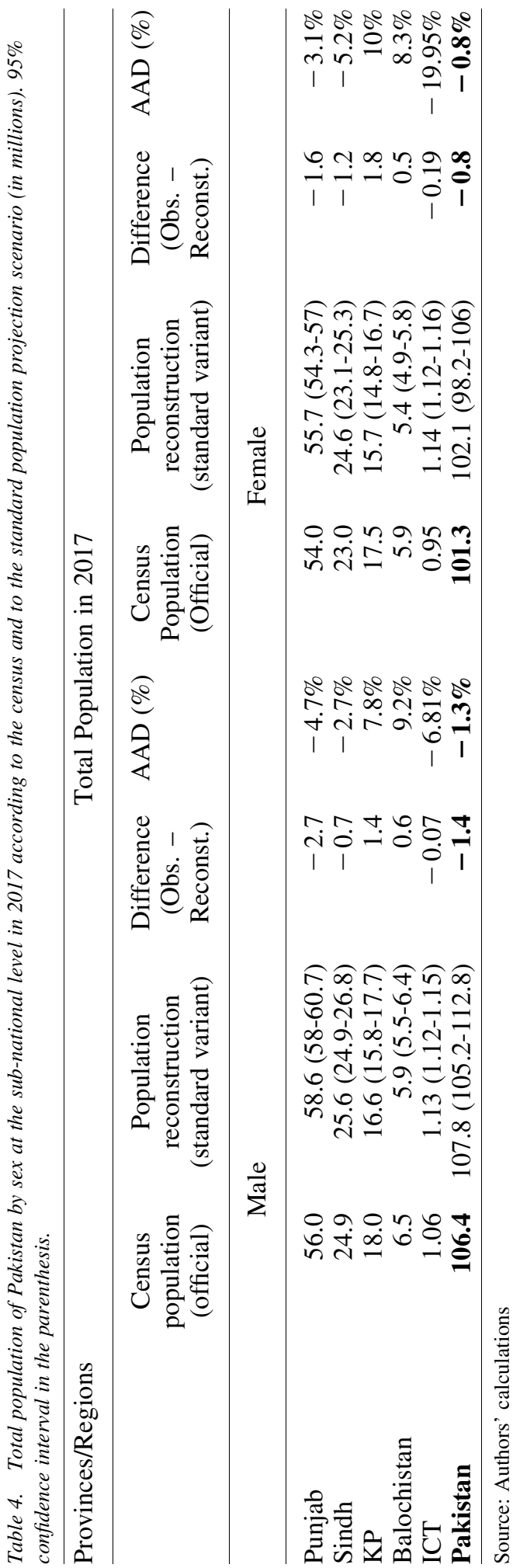


in Punjab and KP have migrated to other countries in 2017, about 3.7 million and 2.5 million respectively. Similarly, all other provinces and regions have minor net negative international migration (see Table 3).

Table 4 shows the difference in population between the reconstructed 2017 population and the enumerated population from the census by sex. At the national level, the reconstructed male and female populations are respectively 1.4 million and 0.8 million larger than in the census, hence a marginal difference of $1.3 \%$ for men and $0.8 \%$ for women.

However, we find more significant variations by sex at the sub-national level. In Punjab, the census population is much smaller than the reconstructed population for both men and women, 2.7 million for men (AAD: $-4.7 \%$ ) and 1.6 million for women (AAD: $-3.1 \%$ ). The retrospective population projections indicate that the difference between census and reconstructed population in Sindh is 0.7 million for men and 1.2 million for women in 2017, respectively. Similarly, the difference in KP is 1.4 million for men and 1.8 for women in 2017. For ICT and Balochistan, though the difference for both male and female population is trivial in absolute number (for men: 0.1 million and 0.6 million, and for women: 0.2 million and 0.5 million, respectively), AADs are significantly higher, compared to the other provinces. Mid-year estimates of population by age-sex for all provinces and federal level along with demographic parameters for reconstruction exercise are given in online supplementary material.

\section{Study Limitations}

This article has some limitations, which must be pointed out. First, there is the inherent weakness of DA, which does not measure census coverage error as PES would. Moreover, the fact that the DA is performed on a long period of 19 years is a strong drawback.

The second constraint is that the reference census date to compare the census and reconstructed results is not accurately specified, because of the long duration of the enumeration period of the census. The census enumeration was divided into two phases and completed in 70 days: the first phase was from 15 March to 13 April 2017, and the second phase from 25 April to 24 May 2017. Because of the small distortion in the net undercount, we used 15 April 2017 as a reference date.

Thirdly, a DA would ideally require that the population by age and sex to be available from two successive censuses. Assessment of age-heaping and under-enumeration in both data set is typically the first step taken in any DA. In an earlier section, we discussed the degree of accuracy of the 1998 census and adjusted the base-year population for undercount in the 0-4 age group and other issues with the age and sex distribution, which are common in census results in low-income countries. However, we had to take the 2017 census total population at face value, because, unfortunately, at the time this analysis was conducted (and up to the end of March 2021) data by single years of age were not available for the 2017 census. However, and based on the past assessment of the census data quality in Pakistan, the 2017 census age-sex distribution would likely be distorted by problems of age heaping and under enumeration like prior censuses. This could potentially create a bias in the comparison of the 2017 census population with the reconstructed population.

Finally, we have collected many surveys to come up with the demographic components of intercensal change, and we rely on their quality and representativeness that may not be 
optimal. Moreover, in many cases, we used indirect methods to come up with the estimates and this may induce some uncertainties/errors in the data. This is particularly the case for the internal migration estimates that could bias the intercensal results, especially since we noticed that the results of the reconstruction are highly sensitive to the level of internal migration for some provinces.

\section{Conclusion}

The census provides a unique opportunity to get reliable and comprehensive estimates of various socio-demographic variables. The mechanisms to assess the quality of the 2017 census in Pakistan were not part of the statistical operation. In this context, DA provides a tool to check potential concerns with the quality of the census data. Utilizing all available empirical evidence, we derive estimates of fertility, mortality, and migration flows that allow us to project retrospectively the 2017 population by age and sex at sub-national level from the 1998 base-year, with some limitations explained earlier.

The reconstructed estimates of mortality and fertility give a consistent picture of demographic developments in each province and region over the last three decades. Although the historical trend is not available, mortality has continued to fall from 1980s in all provinces. Child mortality was the first to drop, followed somewhat later by declines in infant mortality at varying rates at sub-national level, slower in Punjab and Sindh compared to other regions and provinces. Sub-national heterogeneity was also observed for life expectancy at birth for men and women alike: the decline was slow in Punjab, Sindh, and Balochistan and rapid in other provinces and regions. In the 1990s and 2000s, the decline in fertility followed mortality improvements, across all provinces and regions. However, fertility remains relatively high at the sub-national level, above three children per woman in 2017. This study was largely descriptive and data-driven, and the social and economic factors that contributed to demographic change clearly deserve in-depth analysis.

International and internal migration flow emerge as important sources of population change within and between the sub-national levels in Pakistan. Despite the recognized importance of migration flows, remarkably little progress has been made to estimate them reliably and to measure their impact on population dynamics and socio-economic development in Pakistan. Our estimates shows the expected variation in the incidence of internal migration with Punjab, Sindh, and ICT as net-receivers during the last 15 years.

Our analysis showed some interesting findings. First, that at the national level, the standard reconstruction leads to results close to that of the census. There are more differences at the sub-national level with the standard variant leading to larger populations in Punjab, Sindh, and ICT compared to the census and lower population in KP, and Balochistan. Second, we show that the reconstruction is highly sensitive to internal migration.

This analysis has emphasized the importance of independent analysis of census data using DA, particularly in low-income countries. While the analysis pointed out the possibility of under- and over-coverage at the sub-national level, there are too many uncertainties in the data used for the reconstruction to be certain about it. However, this analysis should prompt the government and the international community to prepare 
for the next census in Pakistan to ensure the high quality of the enumeration procedure. In particular, the census should use both de-jure and de-facto population count within a short enumeration period (ideally three to five days), and collect the information on the previous place of residence and duration of stay at current residence (status of internal migration). Finally, in order to assess the accuracy of the census and to determine how future censuses can be improved, DA is an important tool for evaluating net coverage error in census data and should become a systematic instrument, in addition to PES.

\section{References}

Ali, S.M., and M. Sultan. 2003. "Age and Sex Distribution of 1998 Census: An Evaluation.” In Population of Pakistan: An Analysis of 1998 Population and Housing Census. Edited by A. Kemal, M. Irfan and N. Mehmood, 95-119. Islamabad: Pakistan Institute of Development Economics (PIDE) and UNFPA, Islamabad.

Abel, G. 2013. "Estimating global migration flow tables using place of birth data." Demographic Research, 28: 505-546. DOI: https://dx.doi.org/10.4054/DemRes.2013. 28.18.

Abel, G., and N. Sander. 2014. "Quantifying global international migration flows." Science, 343: 1520-1522. DOI: http://doi.org/10.1126/science.1248676.

Abel, G. 2017. "Estimates of global bilateral migration flows by gender between 1960 and 2018." International migration review, 52 (3): 2018. DOI: https://doi.org/10.1111/imre. 12327.

Abel, G. 2018. migest: Methods for the Indirect Estimation of Bilateral Migration. $R$ package version 1.8.5. R Core Development Team. Available at: https://cran.r-project. org/package $=$ migest (accessed December 2017).

Arriaga, E.E., P. Johnson, and E. Jamison. 1994. Population Analysis with Microcomputers. U.S. Census Bureau, International Programs Software. Available at: https://www2.census.gov/software/pas/documentation/pamvi-archive.pdf

BEOE (Bureau of Emigration and Overseas Employment). 2019. Workers registered for overseas employment by bureau of emigration and overseas employment 1981-2019. Islamabad. Available at https://beoe.gov.pk/files/statistics/2019/province.pdf (accessed June 2018).

Booth, H. 1984. “Transforming Gompertz's Function for Fertility Analysis: The Development of a Standard for the Relational Gompertz Function.” Population Studies, 38(3): 495-506. DOI: https://doi.org/10.1080/00324728.1984.10410306.

Borges, G., and N. Sacco. 2016. Has census coverage in Latin America improved with time?. International Seminar on Registering and Counting the Population: The production and exploration of census information from early modern times to the end of 20th century. Unicamp, Nepo, IUSSP, Campinas - Sao Paulo. Barzil. Available at: https://www.aacademica.org/nicolas.sacco/109.pdf (accessed June 2018).

Cibea, A., S. Dearing, G. Gures, A. Rehman, and I. Wolfsgruber. 2013. A silk routes partnership for migration: Pakistan migration country report, Vienna: International Centre for Migration Policy Development. 
Daponte, B.O., J.B. Kadane, and L.J. Wolfson. 1997. "Bayesian demography: Projecting the Iraqi Kurdish population, 1977-1990." Journal of the American Statistical Association. 92(440): 1256-1267. DOI: https://doi.org/10.2307/2965396.

Feeney, G., and I. Alam. 2003. "Fertility, Population growth and accuracy of census enumeration in Pakistan: 1961-1998." In Population of Pakistan: An Analysis of 1998 Population and Housing Census. Edited by A. Kemal, M. Irfan and N. Mehmood: 77-88. Islamabad: Pakistan Institute of Development Economics (PIDE) and UNFPA. Gazdar, H. 2003. A review of migration issues in Pakistan, Collective for Social Science Research. Karachi, Pakistan. Available at: http://www.researchcollective.org/ Documents/A_Review_of_Migration_Issues_in_Pakistan.pdf (accessed June 2018).

George, M., K. Stanley, D. Swanson, and J. Tayman. 2004. "Population Projections." In The Methods and Materials of Demography. 2nd Edition. Edited by D.A. Swanson, and J.S. Siegel, 561-601. Emerald Group Pub Ltd.

Haman, J., and M. Avery. 2020. ciTools: "Confidence or Prediction Intervals, Quantiles, and Probabilities for Statistical Models.” R package version 0.6.0. Available at: https:// cran.r-project.org/package $=$ ciTools (accessed December 2020).

Hill, K., M. Inoue, M.Z. Oestergaard, and UN IGME. 2012. "Child Mortality Estimation: Accelerated Progress in Reducing Global Child Mortality, 1990-2010.” PLoS Medicine, 9(8): 1-11. DOI: https://doi.org/10.1371/journal.pmed.1001303.

Irfan, M. 1986. Mortality and health issues: mortality trends and patterns in Pakistan, Asian Population Studies Series \# 75. Economic and Social Commission for Asia and the Pacific Bangkok, Thailand. Available at https://mpra.ub.uni-muenchen.de/38619/ 1/MPRA_paper_38619.pdf (accessed June 2018).

Karim, M., and A. Nasar. 2003. "Migration patterns and differentials in Pakistan: Based on the analysis of 1998 census data." In Population of Pakistan: An Analysis of 1998 Population and Housing Census. Edited by A. Kemal, M. Irfan, and N. Mehmood. Pakistan Institute of Development Economics (PIDE), UNFPA, Islamabad.

KC, S., M. Wurzer, M. Speringer, and W. Lutz. 2018. "Future population and human capital in heterogeneous India." Proceedings of the National Academy of Sciences (PNAS) of the United States of America, 2-6. DOI: https://doi.org/10.1073/pnas. 1722359115

Kemal, A., M. Irfan, and N. Mahmood. 2003. "1998 Population and Housing Census - An Overview." In Population of Pakistan: An analysis of 1998 Population and Housing Census. Edited by A.R. Kemal, M. Irfan, and N. Mahmood, 3. Islamabad: Pakistan Institute of Development Economics (PIDE) and UNFPA, Islamabad.

Kleiber, C., and A. Zeileis. 2008. "Applied Econometrics with R.” New York: SpringerVerlag. Available at: https://cran.r-project.org/package = AER (accessed June 2018).

Lee, R.D. 1974. "Estimating series of vital rates and age structures from baptisms and burials: A new technique, with applications to pre-industrial England." Population Studies, 28 (3): 495-512. DOI: https://doi.org/10.2307/2173642

Lee, R.D. 1985. "Inverse projection and back projection: A critical appraisal, and comparative results for England, 1539 to 1871.” Population Studies, 39(2): 233-248. Available at: https://www.jstor.org/stable/2174489. 
Lee, R.D. 1993. "Inverse projection and demographic fluctuations." In: Old and New Methods in Historical Demography. Edited by D.S. Schofield, and R. Reher, 7-28. Clarendon Press: Oxford.

Mariani, F., A. Perez-Barahona, and N. Raffin. 2009. Life expectancy and the Environment, Bonn, Germany: The Institute for the Study of Labor (IZA). Available at: http://ftp.iza.org/dp4564.pdf (accessed June 2018).

Marti, M., and C. Rodenas. 2007. "Migration Estimation Based on the Labour Force Survey: An EU-15 Perspective.” International Migration Review. Volume 41: 101-126. DOI: https://doi.org/10.1111/j.1747-7379.2007.00058.x.

Ministry of Overseas Pakistanis and Human Resource Development. 2016. Labor Migration from Pakistan: 2015 status report, Islamabad: Goverment of Pakistan. Available at: https://www.ilo.org/wcmsp5/groups/public/—asia/—ro-bangkok/—ilokathmandu/documents/publication/wcms_514139.pdf (accessed June 2018).

Ministry of States and Frontier Regions, Population Census Organization, and UNHCR. 2005. Census of Afghans in Pakistan 2005, Ministry of States and Frontier Regions; Population Census Organization; and UNHCR Islamabad. Available at: https://reliefweb.int/sites/reliefweb.int/files/resources/89D638A6EECC6CF18525708A005473F6unhcr-afg-05sep.pdf (accessed June 2018).

Minnesota Population Center. 2017. Integrated Public Use of Microdata Series, International: Version 6.5 [data set]. Minneapolis, MN: University of Minnesota. Available at: https://international.ipums.org/international/ (accessed January 2018).

Murray, C., T. Laakso, K. Shibuya, K. Hill, and A.D. Lopez. 2007. "Can we achieve Millennium Development Goal 4? New analysis of country trends and forecasts of under-5 mortality to 2015." Lancet, 370 (9592): 1040-1054. DOI: https://doi.org/10. 1016/S0140-6736(07)61478-0.

National Research Council. 2000. Beyond Six Billion. Edited by John Bongaarts and Rodolfo A. Bulatao. Washington D.C. National Research Council. Available at: https:// www.nap.edu/catalog/9828/beyond-six-billion-forecasting-the-worlds-population.

National Institute of Population Studies (NIPS), and ICF. 1992. Pakistan Demographic and Health Survey 1990-1991. Islamabad, Pakistan, and Rockville, Maryland, USA: NIPS and ICF. Available at: Microlevel data sets available for registered user: https://dhsprogram.com/data/available-datasets.cfm (accessed February 2017).

National Institute of Population Studies (NIPS), and ICF. 2008. Pakistan Demographic and Health Survey 2006-2007. Islamabad, Pakistan, and Rockville, Maryland, USA: NIPS and ICF. Available at: Microlevel data sets available for registered user: https://dhsprogram.com/data/available-datasets.cfm (accessed February 2017).

National Institute of Population Studies (NIPS), and ICF. 2013. Pakistan Demographic and Health Survey 2012-2013. Islamabad, Pakistan, and Rockville, Maryland, USA: NIPS and ICF. Available at: Microlevel data sets available for registered user: https://dhsprogram.com/data/available-datasets.cfm (accessed February 2017).

National Institute of Population Studies (NIPS), and ICF. 2019. Pakistan Demographic and Health Survey 2017-2018. Islamabad, Pakistan, and Rockville, Maryland, USA: NIPS and ICF. Available at: Microlevel data sets available for registered user: https://dhsprogram.com/data/available-datasets.cfm (accessed February 2019). 
Pakistan Bureau of Statistics. 2015. "Pakistan Social and Living Standard Measurement Survey (PSLMs): 2005-2006, 2007-2008 and 2013-2014 rounds". Ministry of Planning Development and Special Initiatives, Islamabad, Government of Pakistan.

Pakistan Bureau of Statistics. 2017. Provisional Summary Results of 6th Population and Housing Census, Planning Development and Special Initiatives, Islamabad, Government of Pakistan.

Pedersen, J., and J. Liu. 2012. "Child Mortality Estimation: Appropriate time periods for child mortality estimates from full birth histories." PLOS Medicine, 9(8): 1-13. DOI: https://doi.org/10.1371/journal.pmed.1001289.

R Development Core Team. 2018. R: A language and environment for statistical computing. Vienna, Austria: R Foundation for Statistical Computing. Available at: https://www.r-project.org/.

Raftery, A., N. Lalic, and P. Gerland. 2014. "Joint probabilistic projection of female and male life expectancy." Demographic Research, 30: 795-822. DOI: https://dx.doi.org/ 10.4054/DemRes.2014.30.27.

Raymer, J., and A. Rogers. 2006. Applying Model Migration Schedules to Represent AgeSpecific Migration Flows, Working paper POP2006-03. Boulder: Institute of Behavioral Sciences. Available at: https://ibs.colorado.edu/pubs/pop/pop2006-0003.pdf (accessed June 2018).

Rees, P., M. Bell, D. Duke-Williams, and M. Blake. 2000. "Problems and solutions in the measurement of migration intensities: Australia and Britain compared." Population Studies. Volume 54: 207-222. DOI: https://doi.org/10.1080/713779082.

Robinson, J. 2010. Coverage of Population in Census 2000 based on Demographic Analysis: The History Behind the Numbers, Washington, D.C.: US Census Bureau. Available at: https://www.census.gov/content/dam/Census/library/working-papers/ 2011/demo/POP-twps0091.pdf (accessed October 2017).

Rogers, A., and J. Castro. 1981. Model migration schedules, RR-81-30. Vienna: International Institute for Applied System Analysis. Available at: http://pure.iiasa.ac.at/ id/eprint/1543/1/RR-81-030.pdf (accessed June 2018).

Pelletier, F. 2020. Census counts, undercounts and population estimates: The importance of data quality evaluation. Population Division Technical Paper No. 2020/02. New York: United Nations Department of Economic and Social Affairs. Available at: https://www.un.org/development/desa/pd/sites/www.un.org.development.desa.pd/files/files/documents/2020/Oct/unpd_2020_tp_population_estimates.pdf (accessed October 2017).

Rukanuddin, A., and N. Farooqui. 1987. The State of Population of Pakistan. National Institute of Population Studies (NIPS), Islamabad.

Sathar, Z. 2007. "Stagnation in Fertility Levels in Pakistan." Asia-Pacific Population Journal 22(2): 113-131. DOI: https://doi.org/10.18356/8302f8fc-en.

Sathar, Z., M.A. Wazir, and M. Sadiq. 2014. Prioritizing family planning for achieving provincial maternal child health and development goals, Islamabad: Population Council. Available at: https://www.popcouncil.org/uploads/pdfs/2014RH_Prioritizing FP_RAF-Report.pdf (accessed January 2019). 
Sawyer, C. 2012. "Child Mortality Estimation: Sex differences in childhood mortality since the 1970s." PLoS Medicine, 9(8): 1-18. DOI: https://doi.org/10.1371/journal. pmed.1001287.

Schoumaker, B. 2013. "A Stata module for computing fertility rates and TFRs from birth histories: tfr2.” Demographic Research, 28: 1093-1144. DOI: https://dx.doi.org/10. 4054/DemRes.2013.28.38.

Siegel, J.S., and D.A. Swanson. 2004. The Methods and Materials of Demography. Second Edition. Elsevier Academic Press, London. UK.

Silva, R. 2012. "Child Mortality Estimation: Consistency of under-five mortality rates estimates using full birth histories and summary birth histories." PLOS Medicine, 9(8): 32-45. DOI: https://doi.org/10.1371/journal.pmed.1001296.

Spoorenberg, T. 2012. "Demographic Changes in North Korea: 1993-2008." Population and Development Review. 38(1): 133-158. DOI: https://doi.org/10.1111/j.1728-4457. 2012.00475.x.

Spoonrenberg, T. 2013. "Demographic Changes in Myanmar since 1983: An examination of official data.” Population and Development Review. 39(2): 309-324. DOI: https:// doi.org/10.1111/j.1728-4457.2013.00593.x.

StataCorp. 2013. Stata Statistical Software: Release 13. College Station, TX: StataCorp LP. Available at: https://www.stata.com/.

Planning and Development Department, Govt. of AJ\&K. 2018. Azad Jammu and Kashmir Statistical Yearbook 2017, Muzaffarabad, Govt. of AJ\&K. Available at: https://www. pndajk.gov.pk/uploadfiles/downloads/Statistical\%20Book\%202017\%20Final.pdf (accessed January 2018).

U.S. Bureau of Census. 1985. Evaluating Censuses of Population and Housing. Washington, D.C.: U.S. Bureau of Census. Available at: https://unstats.un.org/unsd/ demographic/meetings/wshops/Jordan_21Nov10/Manuals/USA_Evaluating_Censuses.pdf (accessed October 2017).

UN IGME. 2015. Levels and trends in child mortality, Estimates developed by UN Interagency group for child mortality estimation, New York: United Nations Children's Fund, World Health Organization, The World Bank, and United Nations Population Division. Available at: https://www.unicef.org/media/files/IGME_Report_Final2.pdf (accessed November 2017).

UN Office for the Coordination of Humanitarian Affairs (OCHA). 2017. Pakistan: KP and FATA - Areas of Displacement, Hosting and Returns as of 31 October 2017. Islamabad: UNOCHA. Available at: https://reliefweb.int/sites/reliefweb.int/files/ resources/pak708_conflict_idps_fatakp_v68_a3_p_20180613.pdf (accessed September 2018).

United Nations. 2008. Principles and recommendations for population and housing censuses Revision 2, New York: Statistics Division, DESA. Available at: https:// unstats.un.org/unsd/demographic/meetings/egm/NewYork/2014/P\&R_Revision3.pdf (accessed February 2018).

United Nations, DESA, Population Devision. 2013. Adolescent Fertility since the International conference on population and development (ICPD) in Cairo, New York: United Nations. ST/ESA/SER.A/337. Available at: https://www.un.org/en/develop- 
ment/desa/population/publications/pdf/fertility/Report_Adolescent-Fertility-sinceICPD.pdf (accessed January 2019).

United Nations, Department of Economic and Social Affairs, Population Division. 2017a. Trends in International Migrant Stock: Migrants by Destination and Origin (United Nations database, POP/DB/MIG/Stock/Rev.2015). New York: Population Division, Department of Economic and Social Affairs. Available at: https://population.un. org/wpp/ (accessed November 2017).

United Nations, Department of Economic and Social Affairs, Population Division. 2017b. World Population Prospects: The 2017 Revision. New York: United Nations, Department of Economic and Social Affairs, Population Division. Available at: https:// population.un.org/wpp/ (accessed November 2017).

United States, Department of Commerce, Bureau of the Census. 1983. "Estimating fertility from data on children ever born. by age of mother". Washington. (International research document. I I)

Wazir, M. 2012. Evolution of population and education in Pakistan: Analysis and projections by provinces. Vienna: Ph.D. Thesis, University of Vienna. Available at: http://othes.univie.ac.at/20317/1/2012-04-19_0746443.pdf (accessed January 2019).

Wazir, M. 2018. "Fertility Preferences in Pakistan." In Family Demography in Asia: A Comparative Analysis of Fertility Preferences. Edited by S. Gietel-Basten, J. Casterline, and M. Choe, 247-259. London: Edward Elgar.

Wazir, A., and A. Goujon. 2019. Assessing the 2017 Census of Pakistan Using Demographic Analysis: A Sub-national Perspective. Working Paper, Vienna: Vienna Institute of Demography: 1-44. Available at: https://www.oeaw.ac.at/fileadmin/subsites/Institute/VID/PDF/Publications/Working_Papers/WP2019_06.pdf (assessed July 2019).

Willekens, F., S. Zinn, and M. Leuchter. 2017. "Emigration rates from sample surveys: An application to Senegal." Demography. 54(6): 2159-2179. DOI: https://doi.org/10.1007/ s13524-017-0622-y.

Wisniowski, A. 2017. "Combining Labour Force Survey data to estimate migration flows: The case of migration from Poland to the UK." Journal of the Royal Statistical Society: Series A, 180 (1): 185-202. DOI: https://doi.org/10.1111/rssa.12189.

Wheldon, M.C., A.E. Raftery, S.J. Clark, and P. Gerland. 2013. "Reconstructing past populations with uncertainty from fragmentary data." Journal of the American Statistical Association: 108(501): 96-110. DOI: https://doi.org/10.1080/01621459.2012.737729.

Wheldon, M.C., A.E. Raftery, S.J. Clark, and P. Gerland. 2016. "Bayesian population reconstruction of female populations for less developed and more developed countries.' Population Studies: 70(1): 21 -37. DOI: https://doi.org/10.1080/00324728.2016.1139164.

Wrigley, E.A., and R. Schofield. 1981. The Population History of England, 1541-1871: A Reconstruction. Studies in social and demographic history. Edward Arnold London.

Received September 2019

Revised February 2021

Accepted May 2021 